\title{
Flood hazard mapping for data-scarce and ungauged coastal river basins using advanced hydrodynamic models, high temporal-spatial resolution remote sensing precipitation data, and satellite imageries
}

\author{
Manh Xuan Trinh ${ }^{1}$ (D) Frank Molkenthin ${ }^{1}$
}

Received: 24 August 2020 / Accepted: 3 June 2021 / Published online: 16 June 2021

(C) The Author(s) 2021

\begin{abstract}
This paper presents an integrated approach to simulate flooding and inundation for smalland medium-sized coastal river basins where measured data are not available or scarce. By coupling the rainfall-runoff model, the one-dimensional and two-dimensional models, and the integration of these with global tide model, satellite precipitation products, and synthetic aperture radar imageries, a comprehensive flood modeling system for Tra Bong river basin selected as a case study was set up and operated. Particularly, in this study, the lumped conceptual model was transformed into the semi-distributed model to increase the parameter sets of donor basins for applying the physical similarity approach. The temporal downscaling technique was applied to disaggregate daily rainfall data using satellitebased precipitation products. To select an appropriate satellite-derived rainfall product, two high temporal-spatial resolution products $(0.1 \times 0.1$ degrees and $1 \mathrm{~h})$ including GSMaP_ GNRT6 and CMORPH_CRT were examined at 1-day and 1-h resolutions by comparing with ground-measured rainfall. The CMORPH_CRT product showed better performance in terms of statistical errors such as Correlation Coefficient, Probability of Detection, False Alarm Ratio, and Critical Success Index. Land cover/land use, flood extent, and flood depths derived from Sentinel-1A imageries and a digital elevation model were employed to determine the surface roughness and validate the flood modeling. The results obtained from the modeling system were found to be in good agreement with collected data in terms of NSE (0.3-0.8), RMSE (0.19-0.94), RPE (-213 to 0.7\%), F1 (0.55), and F2 (0.37). Subsequently, various scenarios of flood frequency with 10-, 20-, 50-, and 100-year return periods under the probability analysis of extreme values were developed to create the flood hazard maps for the study area. The flood hazards were then investigated based on the flood intensity classification of depth, duration, and velocity. These hazard maps are significantly important for flood hazard assessments or flood risk assessments. This study demonstrated that applying advanced hydrodynamic models on computing flood inundation and flood hazard analysis in data-scarce and ungauged coastal river basins is completely feasible. This study provides an approach that can be used also for other ungauged river basins to better understand flooding and inundation through flood hazard mapping.
\end{abstract}

Extended author information available on the last page of the article 
Keywords Flood hazard - Regionalization methods - Sub-daily rainfall · MIKE models · Calibration and validation · Tra Bong river basin

\section{Introduction}

Fluvial floods and coastal floods caused by high river discharge, high tide, and storm surge, or a combination of those, are some of the most common, dangerous, and devastating natural hazards occurring in coastal river basins, impacting millions of households and communities worldwide. The topics of flood hazards and flood risks have been generally investigated in the past few decades, and many studies have found that flood disasters have tremendously affected the development of the society and the economy of countries (Douglas 2017; Feyen et al. 2009; Tran et al. 2008). Research on flood hazard mapping can be primarily distinguished into two kinds of approaches: (1) Using Geographical Information System (GIS), satellite, and remote sensing products, and historical records (flood traces, flood marks) to investigate flood behaviors and characteristics for mapping floodplains and flood hazards (Chen et al. 2015; Dewan et al. 2007; Luu et al. 2018; Ntajal et al. 2017). It is noted that this approach does not involve flood modeling. Thus, for areas where necessary data are not available or scarce, this approach is a potential option; however, due to lack of flood-related information, the hazards of flood velocity, flood depths, and flood duration are not usually considered in detail. Moreover, the ability to predict and compute future flooding is one of the drawbacks of the methods. (2) Using numerical models to simulate flood flows, aiming to obtain flood characteristics over floodplains for mapping flood hazards (Mani et al. 2014; Nam et al. 2015; Nga et al. 2018; Shrestha et al. 2019a). This approach is commonly used due to its ability to achieve good and reliable results, as well as its flexibility; via this method, flood behaviors and characteristics are clearly investigated. This can be considered as a traditional approach; however, a large amount of basin-related data and required information need to be collected once advanced hydrological and hydraulic models are applied (Prinos 2008). In our study, we attempted to apply an integrated approach that includes both primary approaches above for data-scarce and ungauged coastal river basins. Particularly, some distinct numerical models were linked together as a comprehensive flood modeling system to simulate flooding and inundation in the Tra Bong river basin. In addition, new remote sensing precipitation data and SAR imageries conducted for the study region were examined and validated to use directly or indirectly as input data for the models as well as to support the model calibration and validation processes.

Since the nineteenth century, when the first rainfall-runoff model was introduced, hydrological and hydraulic models have been rapidly developing and widely utilized in hydrology and water resources management all over the world. For a long time, they have become useful and effective tools to address the real hydrological cycle processes, especially in flood inundation modeling, flood risk assessment, and flood forecasting (Horritt and Bates 2002; Teng et al. 2017). However, there are currently still many data-scarce and ungauged river basins, especially in developing countries like Vietnam, or less developed areas. For these river basins, modeling floods and inundation is even more challenging. The regionalization can be defined simply as a methodology of transferring model parameters from nearby gauged river basins to ungauged river basins and may be sufficient for applying hydrological models. Usually, due to the unavailability of long-term flow data in ungauged basins, many efforts have been made to investigate the regionalization 
techniques for streamflow time series generation using various hydrological model-based approaches including conceptual and semi-distributed models. The regionalization basically consists of the four common transfer methods including Arithmetic Mean, Physical Similarity, Spatial Proximity, and Regression (He et al. 2011; Wallner et al. 2013; Swain and Patra 2017; Tegegne and Kim 2018). Boughton and Chiew (2007) applied the Australian Water Balance Model (AWBM) in combination with the multiple linear regressions technique to estimate the average annual runoff for each of 213 catchments of Australia. Two-third of the results were within $25 \%$ of real values. Makungo et al. (2010) used the MIKE11 NAM model to generate natural streamflow using the modified nearest neighbor regionalization approach applied to an ungauged basin in South Africa. The proposed approach showed reasonably good results at daily and sub-quaternary catchment scales. Tegegne and Kim (2018) used a semi-distributed SWAT (Soil and Water Assessment Tool) model with the method of catchment runoff-response similarity to simulate runoff for two ungauged basins in South Korea and Ethiopia. The evaluation results showed at various test-gauging stations from $67 \%$ up to $91 \%$ were reached over the calibration and validation period. In this paper, we proposed a new approach in applying the MIKE11 NAM model for ungauged river basins, in the view of reducing the uncertainty of regionalization approach, to solve the problem of selecting similar or donor basins, and to suit the climate conditions, natural characteristics, and stream gauging station network density of the study basin. Accordingly, the model was transformed from the lumped conceptual model to the semi-distributed model by using sub-basins and Muskingum routing method. Moreover, much fewer works dealt with using coupled hydrological and hydrodynamic models for simulation of flood propagation processes and inundation in ungauged basins. Particularly, in Vietnam, to the best of our knowledge, we are not aware of any previous studies which covered similar topics and study characteristics in the same study area or regions.

Along with the development of mathematical models, the growing availability of distributed remote sensing data with high-resolution and free-of-charge sources, as well as increased computational resources, has reinforced the capability and opportunities for flood inundation modeling. Thus, remote sensing-based analysis of flooding can be implemented rapidly in near real-time and in large-scale applications (Cohen et al. 2019). More recently, many studies have been conducted to utilize satellite-derived data such as satellite precipitation and satellite imagery to enhance model performances of flood inundation. Baldassarre et al. (2009) presented a methodology to calibrate a flood model (LISFLOOD-FP) using ten different flood extent maps derived from coarse resolution (ENVISAT ASAR) and high-resolution (ERS-2 SAR) satellite images. The methodology was applied for a river in the UK and proved to be more reliable than the standard techniques. Nguyen et al. (2016) proposed a method for estimating inundation depths using flood extent information and then compared their results to hydrodynamic simulations. Promising results were found with an estimation precision of $0.02-0.17 \mathrm{~m}$ for two case studies in Vietnam. Chang et al. (2019) proposed a model-aided altimetry-based flood forecasting system for the Mekong River based on an integration of satellite altimetry for water level measurements and the Variable Infiltration Capacity hydrologic (VIC) model. The forecasting capacity of the system in the region outside of the Mekong delta was limited; however, the forecasting system was promising inside the Mekong delta. Corresponding to remote sensing precipitation, Ryo et al. (2014) introduced a method for temporal downscaling of daily gauged precipitation using the Global Satellite Mapping of Precipitation (GSMap) products and further used the downscaled precipitation as the input for a distributed hydrological model. The study illustrated that satellite-based precipitation measurements have potential applications in moderate-sized watersheds. Adjei et al. (2015) conducted a study in which the 
Tropical Rainfall Measuring Mission (TRMM) Multi-Satellite Precipitation Analysis data were used as an input in the SWAT model for runoff simulation. A good correlation and residual variation between model results and gauging stations were observed in the study. It can be observed that the development and availability of remote sensing data in terms of high resolution and accuracy have led to a significant shift in applying hydrological numerical models in general, and for data-poor environments in particular (Bates 2004). In this paper, we examined and evaluated new products of satellite imagery and precipitation conducted for regions in Southeast Asia. The accuracy of two satellite precipitation products was evaluated and compared with sub-daily and daily rain gauge-measured precipitation. An appropriate remote sensing precipitation product was then selected to support the hydrological model setup. Land cover/land use, flood extent, and flood depths derived from SAR imageries were employed to set up and validate the hydrodynamic model. Additionally, flood depths were computed to augment the model calibration process by integrating inundation maps with an associated digital elevation model.

Flood hazard maps usually indicate where the flood characteristics may be dangerous to communities for a defined return period (LAWA 2006). However, in flood hazard mapping, as well as flood risk and damage assessments, many previous studies have primarily focused on floodplain maps complemented with types of flooding such as the flood extent, flood depth, flood velocity, or relevant flow direction. In many cases, e.g. polder areas, lowland areas, or cultivated areas, the duration of inundation can be considered as an important factor for assessing damages and risks (Dang et al. 2011; De Moel et al. 2009). Currently, advanced hydrodynamic models and advances in the computational ability of computers have enabled the calculation of various parameters of flood inundation for a long period of time and large regions. As a result, comprehensive flood hazard assessments that take into account a combination of flood inundation, flood depth, flood velocity, and flood duration are getting more important and necessary in the field of flood risk management for not only gauged basins but also ungauged basins. The hazard maps can be used as a reference that can support flood risk assessments and management as well as help local governments to better understand and manage flood disasters. For these reasons, the objectives of this paper are: (1) to propose an integrated workflow for modeling flood inundation in data-scarce and ungauged coastal river basins and a new approach for the lumped conceptual rainfall-runoff model in applying the regionalization techniques, (2) to investigate the applicability of new remote sensing data of precipitation and imageries with high spatial-temporal resolutions in the study area, and (3) to obtain the flood hazard maps based on flood inundation, flood depth, flood velocity, and flood duration corresponding to various flood probabilities for the case study.

\section{Study area and data}

Vietnam is one of the ten countries most affected by extreme weather events ranked by GermanWatch Global Climate Risk Index (Kreft et al. 2015). The location selected as a case study area is the Tra Bong river basin, which is located in Binh Son district, Quang Ngai province, Central Vietnam (Fig. 1). This province has two river basin systems including Tra Khuc-Ve and Tra Bong, in which the Tra Bong River is located in the North and the Tra Khuc-Ve is located in the South. The population is distributed along the rivers in both rural and urban areas. The eastern part borders the Vietnam's East Sea with a coastline of $54 \mathrm{~km}$. A lot of large or extreme floods have been recorded and have 


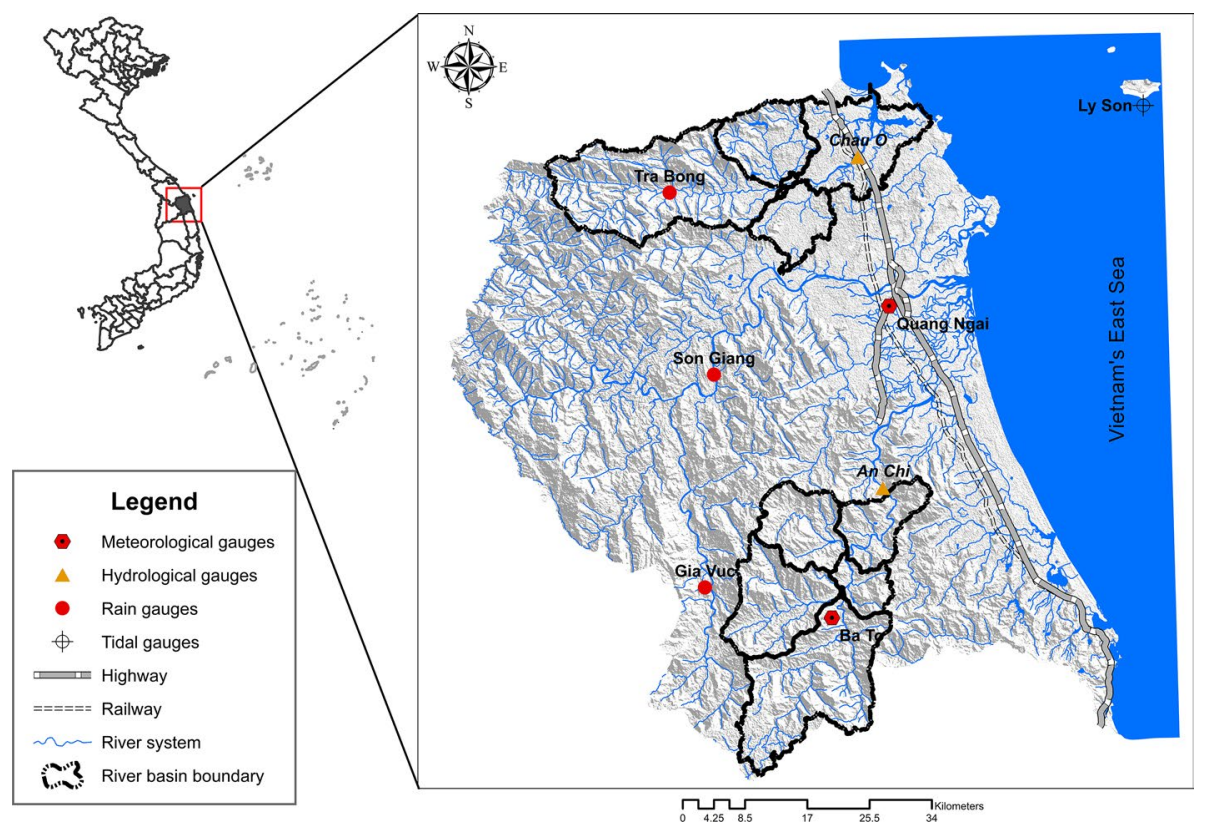

Fig. 1 Location of the study area, the Tra Bong's sub-basins, and An Chi's sub-basins

tremendously impacted the economy, environment, and society in this area recently, including some typical flood events in 1999, 2003, 2007, 2008, 2009, 2013, and 2016 (Nhung 2016). The Tra Bong basin has a total basin area of $700 \mathrm{~km}^{2}$, of which more than $80 \%$ is mountainous or hilly (500-1500 m above mean sea level). The basin topography is characterized as highland and lowland without a transition region in between. The basin has an average altitude of $196 \mathrm{~m}$ above mean sea level and an average slope of approximately $10.9 \%$. The network density is about $0.43 \mathrm{~km} / \mathrm{km}^{2}$. The main river length is $59 \mathrm{~km}$ (AusAID 2003). The basin consists of a main river and many tributaries around it. The river flows through Tra Bong and Son Tinh provinces, passing Chau O Town before splitting into three tributaries in the downstream area. The three tributaries meet again at a confluence before reaching the sea at the estuary $(5 \mathrm{~km}$ upstream from the coast).

The basin is located in a tropical monsoon climate and is affected by the topography of the Truong Son mountain range as well as the climatic phenomena from the sea. A large percentage of the rainfall amount is contributed by typhoons; therefore, most of the floods are a result of typhoons from the sea (Huong 2010). Every year the total rainfall often fluctuates from 2200 to $2500 \mathrm{~mm}$ in the delta areas. In the highland regions, the value varies from 3000 to $3500 \mathrm{~mm}$ and is less than $2000 \mathrm{~mm}$ in the southern areas. Hydrological and meteorological data are very limited in the entire province in general, and in the study basin in particular. The river flow discharge is not measured in the basin despite flooding being one of the most concerning problems. Rainfall is only measured at Tra Bong rain gauge at daily intervals and the river water levels are rarely observed at Chau O (Fig. 1). Moreover, the observed tidal data are not available at the river mouth. For these reasons, the Tra Bong river basin is primarily considered as an ungauged and data-poor coastal river basin. 


\section{Methodology and model evaluation}

\subsection{Methodology}

A workflow chart of the proposed methodology applied for this study, aiming to develop flood hazard maps for basins that experience a lack of data or high-quality data, is shown in Fig. 2. The methodology consists of three main sections including data collection and preparation, rainfall-runoff modeling, and hydrodynamic modeling. These sections are described in detail as following:

(1) Data collection and preparation: A lot of data and basin-related information are required in this step. Due to the lack of information and data scarcity in the target basin, data of a donor basin are collected instead. However, the donor basin also needs to have the nec-

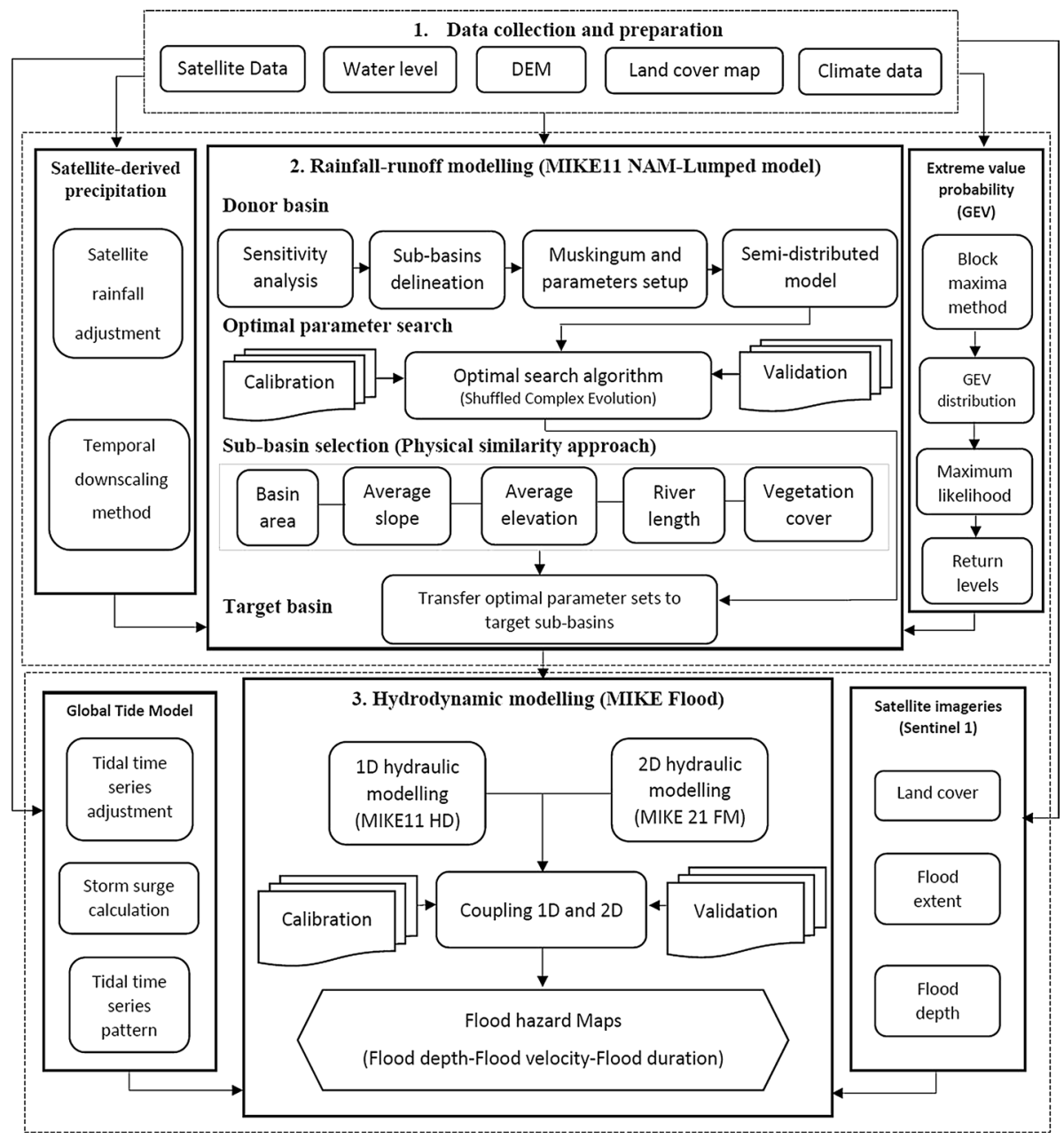

Fig. 2 Methodological workflow chart adopted in the case study 
essary data available. To estimate flood flows from heavy rainfall, it is clear that daily and sub-daily rainfall, evaporation, and discharge need to be collected. The observed tidal and modeled tidal time series are also collected to calculate storm surges. The land cover and terrain data such as river cross sections, geographic maps, and digital elevation models (DEMs) are important for modeling hydraulic flows. The satellite data including remote sensing precipitation and SAR imagery with high temporal-spatial resolution are one of the most essential data for this work.

(2) Rainfall-runoff modeling: The parameter sensitivity analysis is implemented using the Global Sensitivity Analysis method to identify the sensitive parameters for the model calibration. Then, for the model setup, we propose an approach in which the lumped model is transformed into the semi-distributed model aiming to increase the parameter sets of a donor basin for applying the physical similarity approach, which is one of the regionalization methods. For that reason, by delineating the entire basin into small sub-basins, each sub-basin is assigned with a distinguished parameter set, and outflows from sub-basins are combined using Muskingum routing. The satellite precipitation is then utilized to downscale from daily to sub-daily for gauging stations where only daily data are measured. Afterward, the rainfall-runoff model parameters are optimized by observed flood events with various peaks and periods based on the optimization methods (e.g. Shuffled Complex Evolution Algorithm). The physical characteristics of each donor sub-basin are obtained using GIS methods, and its optimal parameter set is transferred to the target sub-basin if their physical characteristics are more or less identical. Eventually, the generalized extreme value (GEV) distribution is chosen to estimate the return level and magnitudes of maximum daily rainfall to compute flood flows as the upstream boundary conditions in the hydrodynamic models.

(3) Hydrodynamic modeling: Runoff estimation of target sub-basins is obtained from the rainfall-runoff model. Flood flow results from this model are used in the 1D flow simulations as upstream and lateral flows. The tidal water levels, which are the downstream boundary conditions of the hydraulic model, are extracted from a GTM and then adjusted with correction factors for two distinct periods: during typhoons and not during typhoons. The 2D model is set up to define a calculated flexible mesh of triangular elements for the floodplain flow simulations. Then, a coupling of the rainfall-runoff model, 1D hydraulic model, and 2D hydraulic model for the river system is developed. The surface roughness coefficients of the floodplain areas are determined from SAR imageries. Historical flood extents and flood depths are also computed using SAR imageries and a DEM for the model calibration and validation. The development of flood hazard maps is based on the results of the maximum flood extent, flood depth, flood velocity, and flood duration corresponding to different flood scenarios derived from a combination of extreme rainfall and storm surges for various return periods.

\subsubsection{Rainfall temporal downscaling and satellite rainfall adjustment}

The accuracy of precipitation measurement is of utmost importance for modeling runoff from rainfall and forecasting extreme flood events as well as other natural hazards and disasters. However, sub-daily or short time step climate data such as rainfall and evaporation are not often available for many gauging stations in developing countries, or less developed areas (Ozawa et al. 2011; Ryo et al. 2014; Ostad-Ali-Askari et al. 2020). Particularly, in flood modeling, short-duration records as inputs for rainfall-runoff modeling play a crucial role in simulating flood flows. Using daily time 
steps of input data for hydrological models might lead to poor performances in representing flood peak values and timing (Ficchì et al. 2016; Shrestha et al. 2019b). Many global satellite precipitation products have been improving in archiving more accurate data, with higher precision and finer spatial and temporal resolutions (Maggioni et al. 2016). Some of the satellite sources are now free of charge for the hydrology community. Several typical and well-known satellite-based precipitation sources include the products of the TRMM Multi-Satellite Precipitation Analysis, the Global Satellite Mapping of precipitation, and the National Oceanic and Atmospheric Administration Climate Prediction Center morphing (CMORPH) technique. Before applying the temporal downscaling technique, the satellite-derived precipitation products are used to examine the accuracy in comparison with rain gauge measurements to select a suitable product for the study area. After that, the daily rain gauge data are disaggregated to sub-daily by dividing the measured daily rainfall obtained at gauging stations to the accumulated sub-daily rainfall derived from satellite data, and then multiplying with satellite sub-daily rainfall as expressed in the simple formula as follows:

$$
P_{\text {Downscale }(i)}=P_{\text {Sat-subdaily }(i)}\left(\frac{P_{\text {Obs-daily }}}{\sum_{i=1}^{24} P_{\text {Sat-subdaily }(i)}}\right)
$$

where $P_{\text {Downscale }(i)}$ is downscaled rainfall at time $(i) ; P_{\text {Obs-daily }}$ is the observed daily rainfall; $\Sigma P_{\text {Sat-subdaily(i) }}$ is the accumulated sub-daily rainfall derived from satellites for $24 \mathrm{~h}$; $P_{\text {Sat-subdaily }(i)}$ is the sub-daily rainfall at time $(i)$.

For areas where observed rainfall is not available, rainfall can be potentially extracted from satellite-based precipitation products. Even though satellite precipitation estimates have a great potential application, they still contain error characteristics compared to gauging stations, and they must be analyzed and corrected before utilization (Haile et al. 2015; Thanh et al. 2013; Ozawa et al. 2011). To get better performances for hydrological models, we present a correction ratio for the adjustment of satellite rainfall at a local scale. The authors do not try to enhance the accuracy of outputs of satellite products, but simply aim to reduce the gap between observed and predicted data as much as possible. Accordingly, satellite rainfall at an ungauged location can be corrected by using the difference determined among gauged sites and satellite products of surrounding sites. Related equations are suggested based on the Inverse Distance Weight method, which is widely applied in hydrology and described as follows:

$$
\mathrm{Cr}=\frac{\sum_{i=1}^{n} K_{i} \frac{1}{d_{i}^{p}}}{\sum_{i=1}^{n} \frac{1}{d_{i}^{p}}}
$$

where $\mathrm{Cr}$ is the correction ratio; $d_{i}$ is the distance from a given observed gauge $i$ to a given corrected gauge; $K_{i}$ is the correction ratio of gauge $i$ between the observed and the satellite daily precipitation $K_{i}=P_{\mathrm{Obs}(i)} / P_{\mathrm{Sat}(i)}, p$ is the exponential number.

Hence, for areas where measured rainfall is not available, the corrected rainfall is simply expressed as below:

$$
P_{\text {Cor-sat }(i)}=P_{\text {Sat }(i)} \times \mathrm{Cr}
$$

where $P_{\mathrm{Cor}-\mathrm{sat}(i)}, P_{\mathrm{Sat}(i)}$ are the corrected satellite rainfall and satellite rainfall at time $i$. 


\subsubsection{Rainfall-runoff model description}

A hydrological model is illustrated in this paper, namely NAM (Danish: NedbørAfstrømnings-Model), which was originally developed at the Technical University of Denmark (DHI 2017a). The model is a lumped conceptual rainfall-runoff model integrated into the MIKE11 river modeling system, which is developed by the Danish Hydraulic Institute (DHI), Denmark, as an individual module. This model is used for simulating the overland, interflow, and base-flow components of a basin based on a structure of four different storages corresponding to a function of the moisture contents that represent some physical elements of a basin such as snow storage, surface storage, lower zone storage, and groundwater storage (DHI 2017a). Table 1 provides a brief description of the nine major model parameters. More details of these parameters and others can be seen in the documentation of MIKE11, "A modeling system for rivers and channels" (DHI 2017a).

The lumped conceptual rainfall-runoff models are suitable for ungauged or data-poor basins because they require fewer data and information as model inputs, and they are easy to use with the regionalization techniques (Bardossy 2007; Makungo et al. 2010; Merz and Blöschl 2004; Ostad-Ali-Askari et al. 2016, 2019). One of the disadvantages of lumped conceptual models is that the models use assumptions of homogeneity of input data, especially areal basin precipitation. This can lead to some errors of model outputs if rain gauges are not evenly distributed over large areas. To apply the regionalization method, it is necessary to examine as many surrounding gauged basins as possible, in order to gather many parameter sets and reduce errors due to the differences of basin characteristics (Lebecherel et al. 2016; Tegegne and Kim 2018). However, to match the above conditions of the regionalization techniques is sometimes impossible since gauged basins are limited, and the differences in basin areas between the two kinds of basins can be significant in less developed areas.

To mitigate the above issues in this study, we proposed a new approach of transferring parameters, based on a transition of lumped modeling to semi-distributed modeling. The detailed procedures of the proposed method are summarized in the following steps (Fig. 2):

Step 1 The gauged and ungauged basins are delineated into smaller sub-basins using GIS software. The physical sizes of these sub-basins must be approximated to

Table 1 Description of the MIKE11 NAM model parameters (DHI 2017a)

\begin{tabular}{llc}
\hline Parameter & Description & Limit values \\
\hline Umax & Maximum water content in surface storage & $10-20 \mathrm{~mm}$ \\
Lmax & Maximum water content in root zone storage & $50-300 \mathrm{~mm}$ \\
CQOF & Overland flow runoff coefficient & $0.0-1.0$ \\
CKIF & Time constant for interflow & $500-1000 \mathrm{~h}$ \\
CK1,2 & Time constants for routing overland flow & $3-48 \mathrm{~h}$ \\
TOF & Root zone threshold value for overland flow & $0.0-0.99$ \\
TIF & Root zone threshold value for inter low & $0.0-0.99$ \\
TG & Root zone threshold value for groundwater recharge & $0.0-0.99$ \\
CKBF & Time constant for routing base-flow & $1000-4000 \mathrm{~h}$ \\
\hline
\end{tabular}


avoid errors caused by differences in basin areas. The natural characteristics of each sub-basin, such as area, slope, river length, vegetation cover, and average elevation, are calculated in this step.

Step 2 The hydrological models for the gauged and ungauged basins are set up with the initial conditions, model parameters, and meteorological data. Particularly, the gauged basins are set up by adding the well-known routing method, Muskingum, to combine all the sub-basin flows. This routing method is also easy to implement in the ungauged basins and does not require the information of river bed topography.

Step 3 Model parameters are calibrated and validated for each sub-basin of the gauged basins using an optimal parameter search algorithm. In this study, we applied the Shuffled Complex Evolution method (Duan et al. 1993).

Step 4 Once the hydrologically identical sub-basins, based on the similarity of basin natural characteristics, are defined, the final parameter sets for gauged subbasins can be easily transferred to the ungauged sub-basins.

\subsubsection{Hydrodynamic model description}

As mentioned above, hydrodynamic models including 1D models and 2D models have been commonly applied in many studies corresponding to flooding simulations and flood risk management. Most recently, a new hybrid approach for simulating flood flow couples a 1D model for representing flow in river channels with a 2D model for representing the flow in floodplain areas. Since 1D models do not simulate accurate results for a complex 2D topography and do not provide comprehensive information on floodplains, 2D models that can accurately handle this issue are used. Even with the computers commonly available today, one setback of 2D models is that they might not be efficient in terms of computational time (Barthélémy et al. 2018; Rai et al. 2018). In other words, using a coupled approach enables us to take advantage of both models. The hydrodynamic models MIKE11 HD and MIKE21 FM were used in this study for flood simulations in the river and its floodplains, and they were then coupled together by MIKE Flood, which is a dynamic coupling tool.

MIKE Flood is a comprehensive tool for combining the 1D and 2D dynamic models into a single modeling system. The model uses an integrated coupling technique that enables the overflow water from $1 \mathrm{D}$ to $2 \mathrm{D}$ domains by using some defined linkage types. There are five different types of links available in MIKE Flood, including standard, lateral, structure, side structures, and zero flow links (DHI 2019a). The lateral link, which allows a string of MIKE 21 FM elements to be laterally linked to a given reach in MIKE11 HD, is highly recommended to use for this work due to its flexibility. The overland flow is directly connected to the floodplain from the $1 \mathrm{D}$ river model to the 2D floodplain model. Therefore, the river bed topography is not crucial in this case, and the computational time is significantly reduced. Consequently, the model setup is based on the requirements of the mesh generation, and the domain is designed with the mesh in the floodplain and without mesh in the river bed. This approach is suitable for river basins where topographical data of the river bed are limited. For more details of this technique, please refer to Sect. 4.3 of the modeling work. 


\subsubsection{Global tide model and storm surges}

River flow in coastal river basins is usually influenced by high tide as well as storm surges caused by typhoons or cyclones. For modeling hydraulic flows of these basins, tidal time series play an important role as the downstream boundary conditions. Similar to other data, the tide is not commonly gauged in developing countries or might not be publicly available. However, the level of accuracy of GTMs has been improved over the years (Stammer et al. 2014). For that reason, the tidal time series can be extracted from a GTM for model simulations. Here we used the DTU10 model, which is developed by Denmark's National Space Institute. DTU10 has a high spatial resolution of $0.125 \times 0.125$ degrees for the main 10 tidal constituents. The model uses multi-measurements from satellite altimetry as the inputs for sea level residuals analysis such as TOPEX/POSEIDON, Jason-1, and Jason-2 (Cheng and Andersen 2011; DHI 2017b). Similar to other satellite products and modeled results, the model-derived tidal data are validated and adjusted by using gauged stations nearby or close to the study areas aiming to strengthen the accuracy of simulations.

Storm surges caused by extreme events of typhoons or cyclones also increase inundation in coastal river deltas. Storm surge heights are not normally recorded during storm periods. Here we try to compute the heights of storm surges by simply comparing tidal time series at a gauged site, which is affected by the same storms and closest to the study area, with the predicted tidal time series. The main hypothesis here is that the storm surges between two selected locations are correlated in terms of heights and periods. The differential heights are directly added to the tidal water levels extracted for the study site and used as the downstream boundary in the $1 \mathrm{D}$ hydraulic modeling.

\subsubsection{Satellite-derived land cover and flood inundation maps}

Synthetic Aperture Radars (active sensors) have more advantages over the visible and infrared instruments (passive sensors) in penetrating clouds, darkness, and tree canopies at longer wavelengths (Smith 1997). In other words, SARs are not particularly influenced by weather conditions or day and night capacity, and they are very sensitive to water. The percentage of cloud cover over satellite imageries is critical for determining flood inundation or monitoring flood events. Clouds and extended rainfall events occur regularly during the flood season in the study area. Deriving flood-related information from SAR imageries for flood modeling has been done by many studies, illustrating a great potential for application in terms of hydrodynamic modeling (Horritt et al. 2007; Schumann et al. 2007; Baldassarre et al. 2009; Sadeh et al. 2018). Moreover, the dominant land cover type in the selected floodplains is cultivated crops; therefore, the determination of the land cover before or after crop harvesting in relation to flood events is necessary here. To avoid the aforementioned issues, Sentinel-1 SAR is recommended to be used for the derivation of useful data such as the land cover, flood depths, and flood extents for flood modeling.

The Sentinel-1 sensor is currently operated by the European Space Agency (ESA) and it has the mission of conducting C-band imagery operations in four modes with different geometric resolutions $(5-40 \mathrm{~m})$ and coverage $(20-400 \mathrm{~km})$ (https://sentinels.copernicus. eu). Sentinel-1 includes two satellites, Sentinel-1A, launched in 2014, and Sentinel-1B, launched in 2016, providing free continuous imagery for a 6-day and 12-day revisit time. In this study, Sentinel-1A products, including high-resolution images $(10 \mathrm{~m})$ of Level-1 Ground Range Detected (GRD), were downloaded from the Sentinel Data Hub and 
employed to derive land cover/land use for assigning Manning's values, flood water extent, and water depths by integrating with a DEM. The Science Toolbox Exploitation Platform (SNAP) Toolkit developed by ESA was applied to derive the high-resolution flood inundation extent from Sentinel-1 SAR (Mcvittie 2019). The Floodwater Depth Estimation Tool (FwDET) developed as part of the National Aeronautics and Space Administration (NASA) Applied Sciences Mid-Atlantic Communities and Areas at Intensive Risk demonstration project was employed to achieve flood inundation depths (Cohen et al. 2018, 2019).

\subsection{Model evaluation statistics}

The objective functions applied to the performances of the rainfall-runoff modeling and the 1D hydraulic modeling in both calibration and validation processes are the well-known evaluation statistics including Nash-Sutcliffe Efficient (NSE), Root Mean Square Error (RMSE), Relative Peak Error (RPE), and Relative Volume Bias (VB). These metrics are defined as follows:

$$
\begin{gathered}
\mathrm{NSE}=1-\frac{\sum_{i=1}^{n}\left(\mathrm{Obs}_{i}-\mathrm{Sim}_{i}\right)^{2}}{\sum_{i=1}^{n}\left(\mathrm{Obs}_{i}-\overline{\mathrm{Obs}}\right)^{2}} \\
\mathrm{RMSE}=\sqrt{\frac{\sum_{i=1}^{n}\left(\mathrm{Obs}_{i}-\mathrm{Sim}_{i}\right)^{2}}{n}} \\
\mathrm{RPE}=\frac{\operatorname{Max}_{\mathrm{Obs}-\mathrm{Max}_{\mathrm{Sim}}} \times 100 \%}{\operatorname{Max}_{\mathrm{Obs}}} \\
\mathrm{VB}=\frac{\sum_{i=1}^{n}\left(\mathrm{Obs}_{i}-\mathrm{Sim}_{i}\right)}{\sum_{i=1}^{n} \mathrm{Obs}_{i}} \times 100 \%
\end{gathered}
$$

where $\mathrm{Obs}_{i}$ and $\mathrm{Sim}_{i}$ are the observed and simulated variables at time $i$, respectively, $\overline{\mathrm{Obs}}$ and $\overline{\mathrm{Sim}}$ are the average observed and simulated variables, respectively, $\mathrm{Max}_{\mathrm{Obs}}$ and $\operatorname{Max}_{\text {Sim }}$ are the maximum values of observed and simulated variables, $n$ is the number of time steps.

Evaluation of flood extent and flood depths derived from the satellite imagery and the two-dimensional model is based on the measure of fit (F1, F2) suggested by Horritt et al. (2007) and the Root Mean Square Error (Eq. 5).

$$
\begin{gathered}
F 1=\frac{A_{\text {Sat }} \cap A_{\text {Sim }}}{A_{\text {Sat }} \cup A_{\text {Sim }}} \\
F 2=\frac{\left(A_{\text {Sat }} \cap A_{\text {Sim }}\right)-\left[A_{\text {Sim }}-\left(A_{\text {Sat }} \cap A_{\text {Sim }}\right)\right]}{A_{\text {Sat }} \cup A_{\text {Sim }}}
\end{gathered}
$$

where $A_{\text {Sat }}$ and $A_{\text {Sim }}$ are total flooded areas derived from satellite imagery and 2D model, respectively. F1 (Eq. 8) varies from 0 for no match between model and satellite to +1 for 
the best match between model and satellite. F2 (Eq. 9) varies from -1 for over-simulation to +1 for best simulation by a $2 \mathrm{D}$ model.

\section{Results and discussion}

\subsection{Comparison of satellite precipitation datasets}

Recently, many satellite precipitation datasets with various temporal-spatial resolutions have been validated by many studies all over the world at global, regional, and local scales. To the best of our knowledge, not many studies have been done to validate high-resolution satellite precipitation products and using them for hydrologic modeling analysis for regions in Southeast Asia. Therefore, to select an appropriate satellite-derived rainfall product for this study, the authors investigated two high temporal-spatial resolution products $(0.1 \times 0.1$ degrees and $1 \mathrm{~h}$ ) including GSMaP_GNRT6 developed by the Japan Aerospace Exploration Agency (JAXA), Japan and CMORPH_CRT developed by the National Oceanic and Atmospheric Administration-Climate Prediction Center, USA. They are provided throughout the Space-based Weather and Climate Extremes Monitoring Demonstration Projects in East Asia and regions of the Western Pacific. This project is powered by the World Meteorology Organization, the National Meteorological and Hydrological Services, and the Global Satellite-derived Products Providers.

To examine the accuracy of these products, they were validated through comparisons with ground-measured rainfall, in which some common statistical errors were used, including the Correlation Coefficient (R), the RMSE, and the Percentage Bias (PBIAS). On top of that, other statistical errors related to the contingency table-based detection of rain events, including the Probability of Detection (POD), the False Alarm Ratio (FAR), and the Critical Success Index (CSI), were employed. The best performances of these metrics were 1,0 , and 1 , respectively. More information on the formulas of these statistics can be found in Ryo et al. (2014).

The rainfall observation datasets of four rain gauges, including Quang Ngai, Tra Bong, Son Giang, and Ba To (Fig. 1), were selected to validate the two products in this study at 1-day and 1-h temporal resolutions. This selection was made due to the availability of long-term data, in which only Quang Ngai and Ba To observe hourly rainfall. The observed rainfall of the rain season (September to December) of the annual series from 2000 to 2017 was chosen as the reference dataset. The remote sensing rainfall data were extracted at the pixels where the rain gauges are located (Fig. 3). Table 2 shows that on a daily scale, whereby only rain events with the threshold of $50 \mathrm{~mm} /$ day were qualified, GSMaP_GNRT6 and CMORPH_CRT show underestimation due to the PBIAS being negative. The RMSEs are relatively high with $126 \mathrm{~mm} /$ day of the maximum values, the Correlation Coefficient of CMORPH_CRT is much higher than GSMAP_GNRT6, and the PODs of both are impressively very high meaning that all the selected rain events were captured well. Similarly, as for a 1-h scale, in terms of PODs, FARs, and CSIs, the GSMaP_GNRT6 and CMORPH_CRT show good performances, the Correlation Coefficient of CMORPH_CRT, in this case, is higher than the one of GSMAP_GNRT6; however, the Correlation Coefficients are relatively low in both products. Our results confirmed the conclusion of the study reported by Ryo et al (2014), satellite precipitation algorithms generally underestimated rainfall intensity. In general, both products show nearly identical performances; however, a comparison between two 


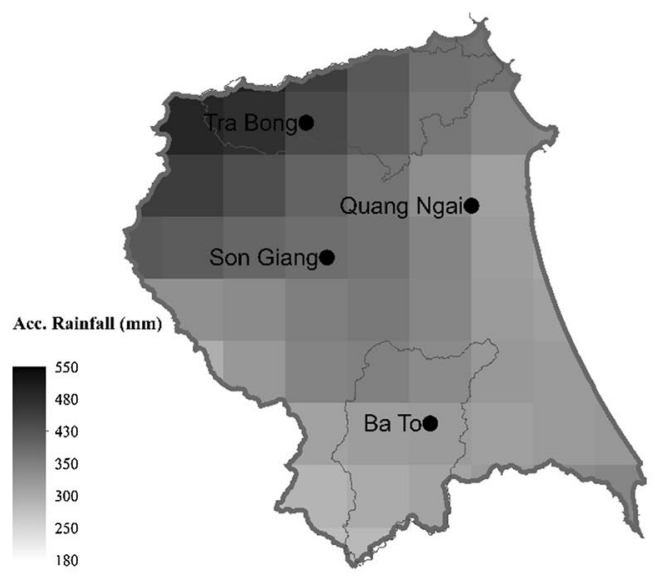

(a)

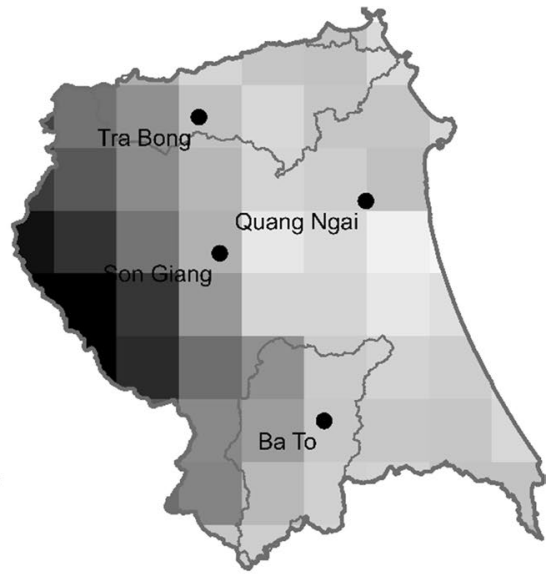

(b)

Fig. 3 Gridded rainfall of GSMaP_GNRT6 (a) and CMORPH_CRT (b)

Table 2 Summary of statistical errors at the two typical locations at 1-h and 1-day scales

\begin{tabular}{|c|c|c|c|c|c|c|c|c|c|c|c|c|}
\hline \multirow[t]{3}{*}{ Rain gauges } & \multicolumn{6}{|c|}{ GSMaP-GNRT6 } & \multicolumn{6}{|c|}{ CMORPH-CRT } \\
\hline & \multicolumn{12}{|c|}{$1 \mathrm{~h}($ threshold $>0.1 \mathrm{~mm} / \mathrm{h})$} \\
\hline & $\mathrm{R}$ & RMSE & PBIAS & POD & FAR & CSI & $\mathrm{R}$ & RMSE & PBIAS & POD & FAR & CSI \\
\hline Quang Ngai & 0.20 & 8.7 & -51.8 & 0.75 & 0.07 & 0.7 & 0.22 & 8.20 & -27.18 & 0.80 & 0.08 & 0.8 \\
\hline Ba To & 0.14 & 10 & -68.1 & 0.53 & 0.06 & 0.5 & 0.24 & 9.60 & -61.10 & 0.63 & 0.06 & 0.6 \\
\hline \multirow[t]{2}{*}{ Rain gauges } & \multicolumn{12}{|c|}{1 day (threshold > $50 \mathrm{~mm} /$ day) } \\
\hline & $\mathrm{R}$ & RMSE & PBIAS & POD & FAR & CSI & $\mathrm{R}$ & RMSE & PBIAS & POD & FAR & CSI \\
\hline Quang Ngai & 0.27 & 95 & -50.60 & 0.97 & - & - & 0.5 & 71 & -27.91 & 1.0 & - & - \\
\hline Ba To & 0.39 & 126 & -69.05 & 0.94 & - & - & 0.6 & 120 & -80.95 & 0.98 & - & - \\
\hline
\end{tabular}

products shows that CMORPH_CRT has a slightly better performance at each gauge. Therefore, the CMORPH_CRT is recommended for this area and further used for the analyses in this work.

The temporal resolution of the rainfall data as an input for hydrological modeling significantly influences the model outputs, especially with small and medium-sized river basins. As mentioned above, daily rainfall is then disaggregated into 1-hourly rainfall by using Eq. 1. The empirical cumulative distribution functions (CDFs) are estimated to evaluate the fit among gauged, satellite, and downscaled hourly rainfall distribution. The empirical CDFs plots with large and extreme observed rain events for two typical rain gauges in 2009 and 2017 are shown in Fig. 4. It can be understood that the empirical CDFs for the satellite precipitation tend to get closer to the observed precipitation for the two gauges meaning that the gap in the temporal resolution of data-poor river basins is partly narrowed down. 

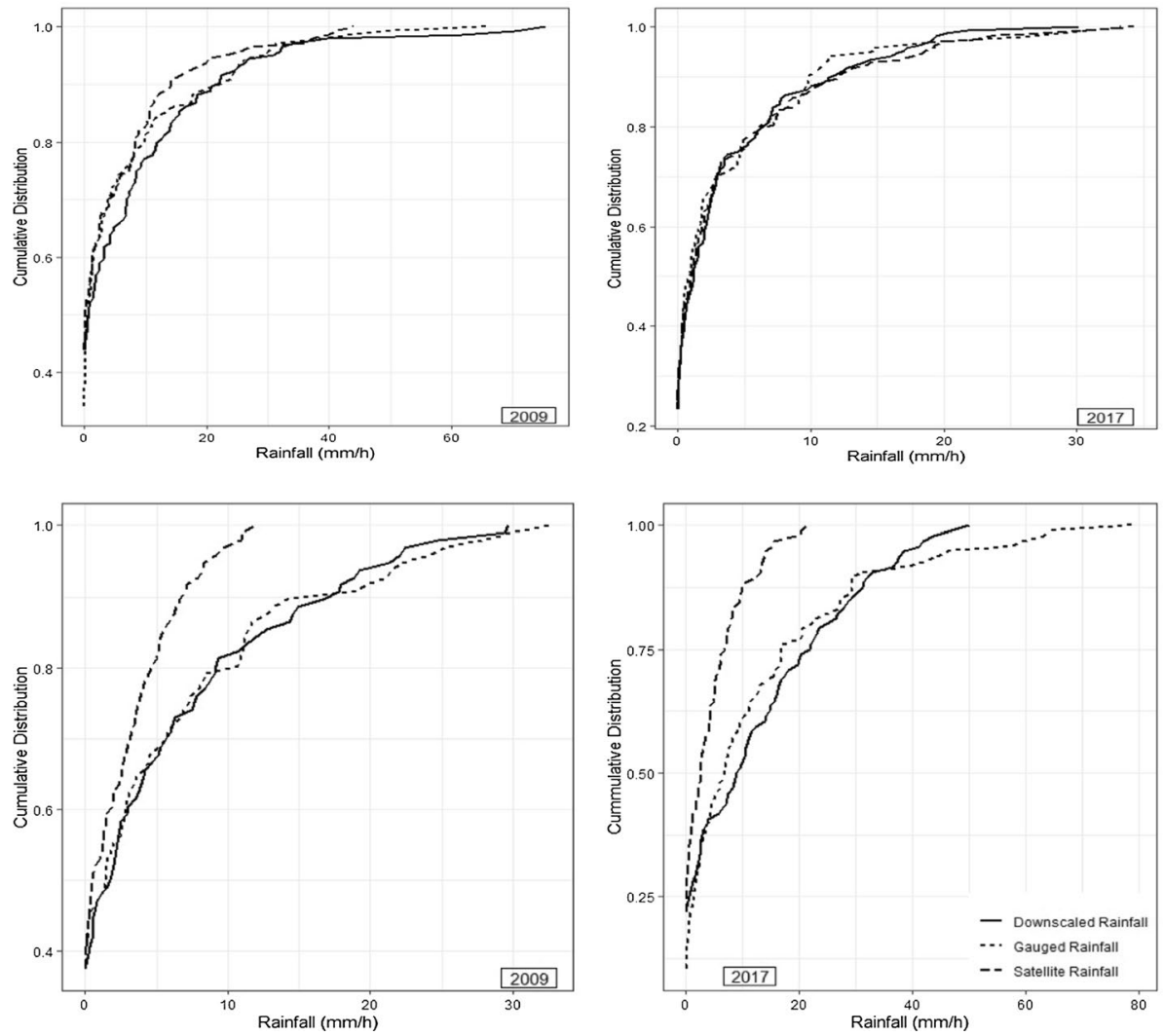

Fig. 4 Empirical cumulative distribution of hourly gauged, satellite, and downscaled extreme rain events at Quang Ngai (upper row) and Ba To (lower row) stations

\subsection{Manning values, flood depth, and flood extent for model calibration and validation}

In $2 \mathrm{D}$ hydrodynamic modeling, surface roughness is one of the major meaningful variables and plays a crucial role in simulating flow in river channels or floodplains. Surface roughness can be commonly expressed by using Manning's roughness coefficient derived from land cover/land use maps. In addition, the land cover/land use maps can be derived from high-resolution SAR sensor data (Engdahl and Hyyppä 2003; Abdikan et al. 2016; Khalil and Saad-ul-Haque 2018). In this work, Sentinel-1A imageries were employed to conduct the land cover map of the floodplain using amplitude information of dual polarimetric SAR imageries (vertical transmit and vertical receive (VV)/vertical transmit and horizontal receive $(\mathrm{VH})$ ) with the single date Level-1 GRD product. Data pre-processing was performed with the SNAP toolbox for the Sentinel 1A image including an imagery subset, radiometric calibration, speckle filter, radiometric terrain correction, and linear to backscattering coefficient decibel scaling (dB) transformation for both $\mathrm{VV}$ and $\mathrm{VH}$ polarizations.

Combining the single VV, VH polarization, and their differences has been proven necessary for image classification (Makinde and Oyelade 2018). A composite of Sigma0_VV, 
Sigma0_VH, and Sigma0 (VV-VH) was used to classify the land cover in this study. The Regions of Interest (ROIs) and the Random Forest Model were applied as the training samples and the supervised classification method, respectively. Additionally, knowing the cropping calendar at the time when the image was captured is very important. The land cover types include water bodies, built-up land, forest (woodland, orchard), cultivated areas (rice crops, pasture, shrub), and bare land. Figure 5a shows the land cover map of the study floodplain illustrating that forest and cultivated areas account for the largest areas, followed by urban and bare land. The range of roughness values for these land cover types was determined based on the studies of McCuen (1998) and George et al. (1989).

The flood inundation extent can also be extracted from Sentinel-1A Level 1 GRD with VV polarization data, which is very sensitive to water. At the end of October 2019, the study area experienced a flood event. During the flooding, a high-resolution satellite image (Sentinel-1A) was acquired at 10:56:35 AM on October 31, 2019 in UTC time. The satellite image was then pre-processed with the same steps mentioned in the land cover processing. Then the flooded areas were firstly visualized by comparing two images: one was captured before the flood event, and the other one was captured during or right after the flood event. Then a binary mask, where the backscatter was below a cutoff threshold of 0.05 (Sigma0_VV <0.05), was created representing the flooded areas (Fig. 5b). Besides the flood extent, the flood depth is also one of the crucial variables for the $2 \mathrm{D}$ model calibration and validation processes. In this study, the FwDET Toolbox integrated into a GIS software was employed to calculate flood depth based on the flood inundation extent map and the DEM ALOS World 3D. The latter product is the global digital surface model with a horizontal resolution of approximately $30 \mathrm{~m}$ provided by JAXA. Figure $5 \mathrm{c}$ presents the flood depth map of the 2019 flood event showing the water depths that change from 0.1 to above $5.5 \mathrm{~m}$.

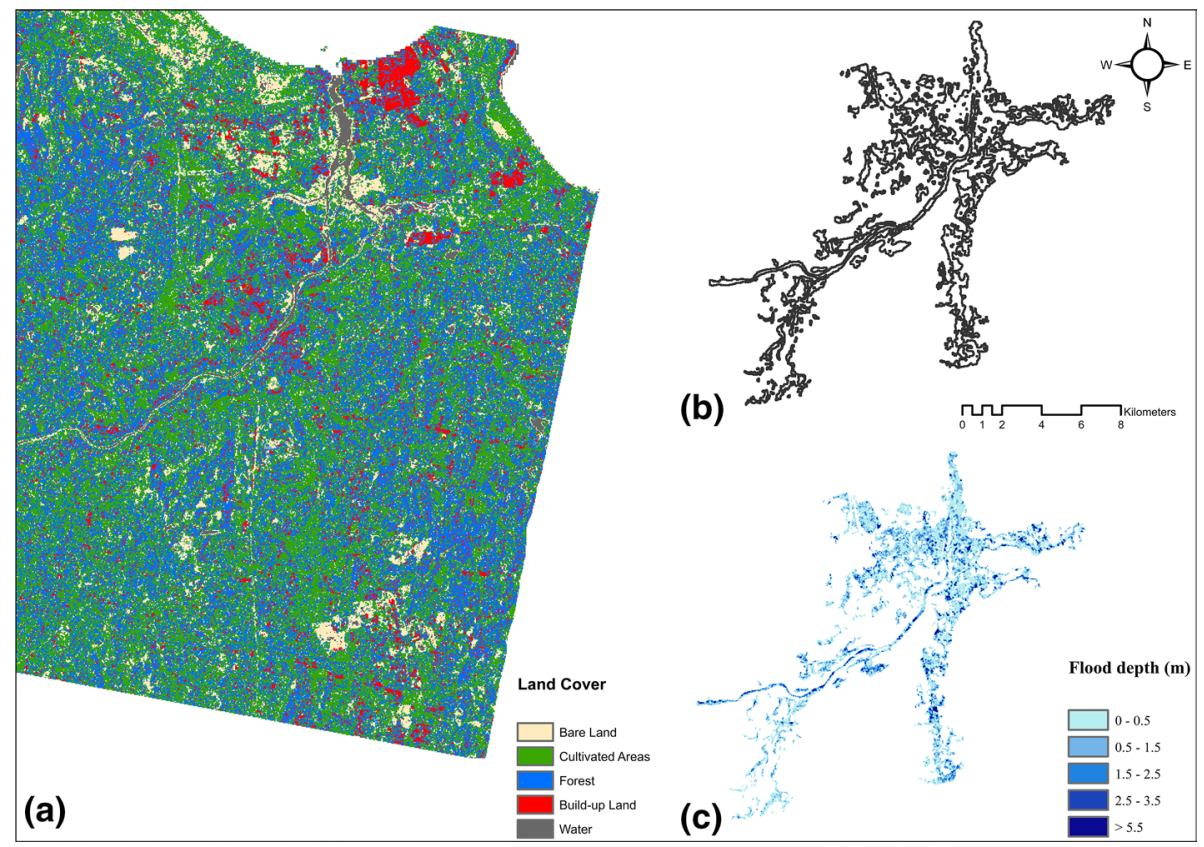

Fig. 5 Land cover (a), flood extent (b), and flood depth (c) of the floodplain 


\subsection{Model setup, calibration and validation}

\subsubsection{Rainfall-runoff modeling}

The rainfall-runoff model was firstly set up for a donor river basin. Due to the lack of gauged basins surrounding the study area, spatial proximity, which is a method of regionalization techniques and based on the spatial distance between basins (He et al. 2011), was used to identify the donor basins. Accordingly, the An Chi basin $\left(690 \mathrm{~km}^{2}\right)$, which satisfies all the assumptions corresponding to the method, was selected as the donor basin. The selected gauged basin was then divided into five smaller sub-basins (Fig. 1) ranging from approximately 50 up to $300 \mathrm{~km}^{2}$. Initial parameters and conditions were entered for each sub-basin and all sub-basins were connected by using three Muskingum reaches. The precipitation and potential evapotranspiration of three gauging stations (An Chi, Ba To, Gia Vuc) were used as the meteorological input data for the model, in which the weighted average areal rainfall was automatically computed.

The parameter sensitivity analysis was analyzed for the donor basin and computed using the method of regional sensitivity analysis. This method is also known as Global Sensitivity Analysis or Generalized Sensitivity Analysis (Song et al. 2015) and has been widely used in the field of hydrology. The Monte Carlo sampling technique was employed to generate 2000 model parameter sets, equivalent to 2000 model runs with hourly time steps, in the ranges of parameter space using a uniform distribution. For model performances, three objective functions were used to screen the sensitivity of the hydrological model including the Average Error, the Root Mean Square Error, and the Error of Maximum Values. Sensitive parameters were identified according to the graphical method by examining the differences in the marginal cumulative distributions (Tang et al. 2007). The results indicated that CQOF, Lmax, CK12, TOF, and TIF, within the nine main parameters recommended by DHI (2017a) (Table. 1), are the most sensitive parameters of the rainfall-runoff model for the basin. These findings are slightly different from those in Makungo et al. (2010) because TOF and TIF were not determined as sensitive parameters in their study. Those model parameters were most heavily focused on during the model calibration process in this work.

The calibration and validation runs of this model were carried out using time periods of 3 and 2 years, respectively, including the largest and extreme flood events that occurred in the years of 1999, 2003, 2009, 2013, and 2017. The rainfall-runoff model was automatically calibrated by applying the Shuffled Complex Evolution algorithm, which is in-built within the model, based on the optimization of several objective functions. Seven of nine main parameters (Fig. 6) mentioned above were used for the optimal search algorithm, in which the TG and CKBF regarding the groundwater recharge and routing were eliminated due to their minor effect and sensitivity on the peak flow, as well as to reduce the computational time.

The goodness-of-fit metrics of NSE, RMSE, RPE, and VB (Eqs. 4-7) were used as the calibration and validation objective functions, and the observed data from the An Chi station were used for these processes. The results of calibration and validation (Fig. 7) show that the hydrograph shapes, as well as the peak flows fit to timing, rate, and volume. The computed NSE values for both processes ranged from 0.61 to 0.92 , and the RMSE values ranged from 245 to $413\left(\mathrm{~m}^{3} / \mathrm{s}\right)$. The RPE and VB values ranged from -1.76 to $3 \%$, and from -0.5 to $10 \%$, respectively. The final rainfall-runoff model parameters were obtained during the calibration as shown in Fig. 6. The CQOF values, which are the most sensitive 

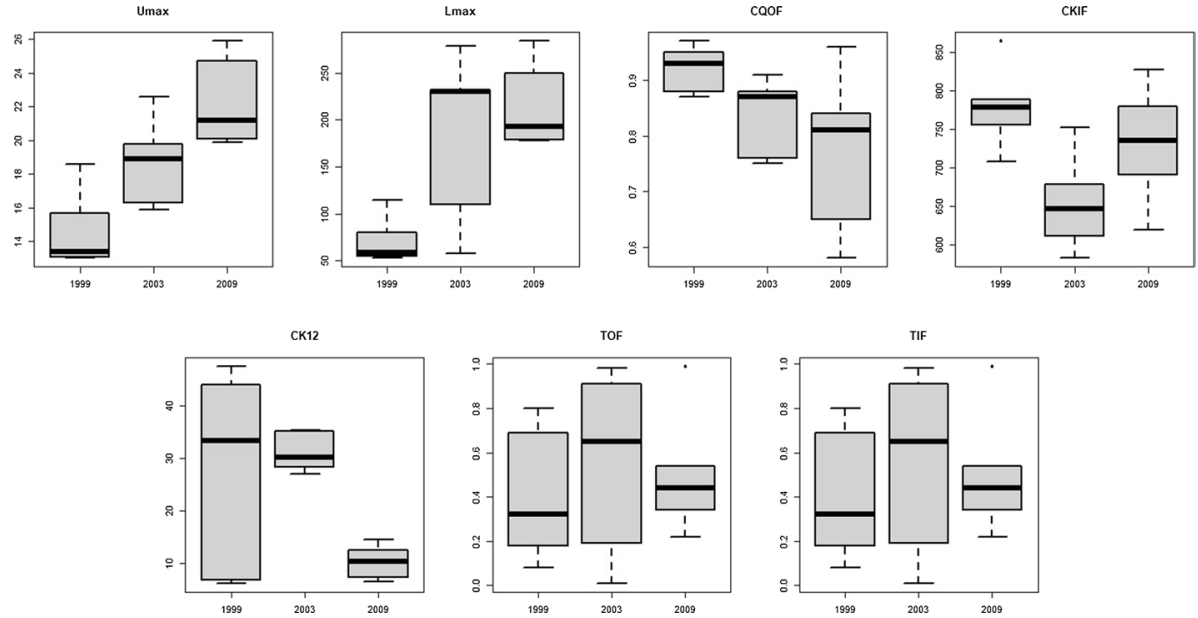

Fig. 6 Optimal model parameters of the donor sub-basins. The box and whisker plots show the 25 th and 75 th percentiles, and range of the data. The lines in the center of the boxes denote the median, and the dots denote outliers
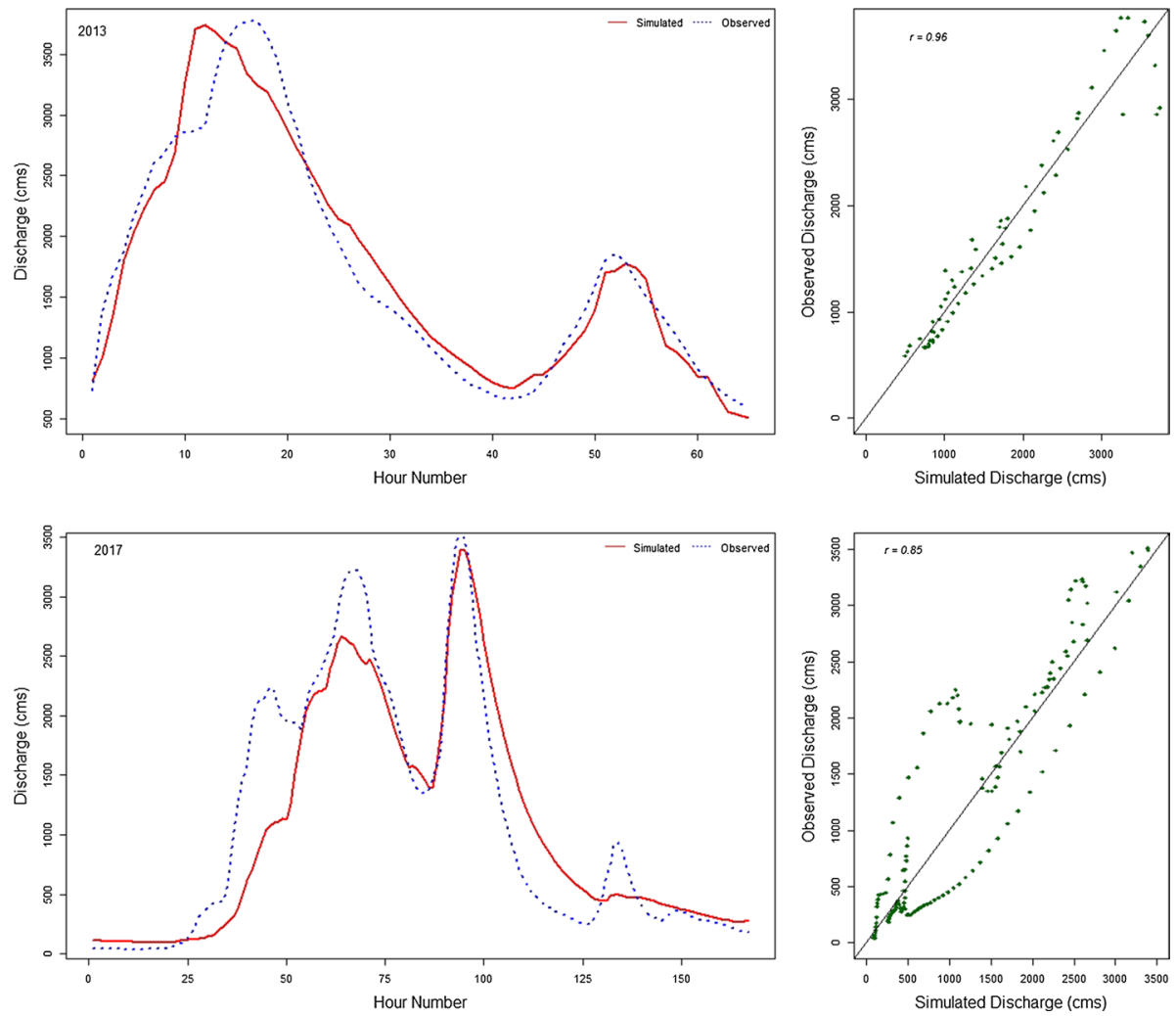

Fig. 7 Hydrographs of measured and simulated streamflow (unit: cubic meter per second) of flood events that occurred in 2013 and 2017 at the donor basin for the validation process 
parameters, varying from 0.5 to 0.96 , were obtained for the sub-basins in the donor river basin with a median of 0.85 . Similarly, CK12 and Lmax varied from 8 to 45 and from 52 to 258 with medians of 25 and 180, respectively. These optimal parameters were then used to transfer to the target river basin in the next step.

As stated in the previous sections, the physical similarity approach was used for transferring optimal parameter sets from gauged ones to ungauged ones in this study. For each ungauged sub-basin, a donor sub-basin was determined based on the most similarity in terms of physical basin descriptors. The entire target basin was delineated into four subbasins (Fig. 1) ranging from 70 up to $313 \mathrm{~km}^{2}$. Several basin attributes have been frequently used for this approach in general, such as basin and river geomorphology, vegetation cover, climate and soil properties, and flow characteristics (Merz and Blöschl 2004; Arsenault and Brissette 2014; Pagliero et al. 2019). Based on the data availability and the physical meanings of model parameters, we selected five major basin characteristics including basin area, river length, vegetation cover, average elevation, and basin slope as major criteria for choosing similar sub-basins. The basin and river geomorphology were computed by using the GIS software with the DEM used as the input. Eventually, the optimal model parameters were added to the target ungauged sub-basins for simulating flood events using the hydrodynamic model.

\subsubsection{Hydrodynamic modeling}

The 1D, 2D hydrodynamic models, and the coupling tool setup are described in detail in this section. The rainfall-runoff model was integrated into the 1D hydraulic model for simulating upstream and lateral inflows of the entire river system of the Tra Bong basin. Figure $8 \mathrm{a}$ shows the hydraulic schematization of the 1D model setup with three reaches including one main river and the other two tributaries, in which the measured river crosssections were entered. Each cross-section contained information of coordinates, elevation, and the Manning's roughness coefficient. The initial Manning's values for the river and its tributaries were chosen from the studies of Chow (1959) and Werner et al. (2005).

The tidal water level time series used as the downstream boundary condition was extracted from the DTU10 model. Cuong et al. (2017) and Bon et al. (2016) showed potential inundation due to storm surges caused by heavy typhoons and super typhoons in the coastal regions of Vietnam. Obviously, storm surges or storm tide cannot be computed in the GTMs. Moreover, Stammer et al. (2014) concluded that GTMs potentially consist of large errors when compared with coastal tide gauges in the near-coastal zone. Thus, the adjustments of extracted tidal water levels are necessary. The seawater level of Ly Son tidal station (Fig. 1), which is closest to the study area (30 km from the estuary), was utilized to investigate the correlation between predicted and observed tidal levels. Accordingly, a linear regressive equation was used to adjust the predicted water levels before a typhoon hitting. During a typhoon landfall, a correction factor (identical to storm surge heights) of 0.5 up to $1.5 \mathrm{~m}$ depending on various magnitudes of typhoons was added to the predicted water level time series.

In the $2 \mathrm{D}$ model, a suitable mesh is essential for obtaining reliable results including a selection of an appropriate domain being modeled and adequate resolution of the bathymetry (DHI 2019b). To generate a mesh for the study area, a DEM was used and subsequently combined with a topography map with a scale of 1:2000. The domain was coordinated in the projection of UTM WGS 84 zone $49 \mathrm{~N}$ and designed with the mesh in the floodplain and the river bed set as undefined values to link with the $1 \mathrm{D}$ model. Figure $8 \mathrm{~b}$ shows a 


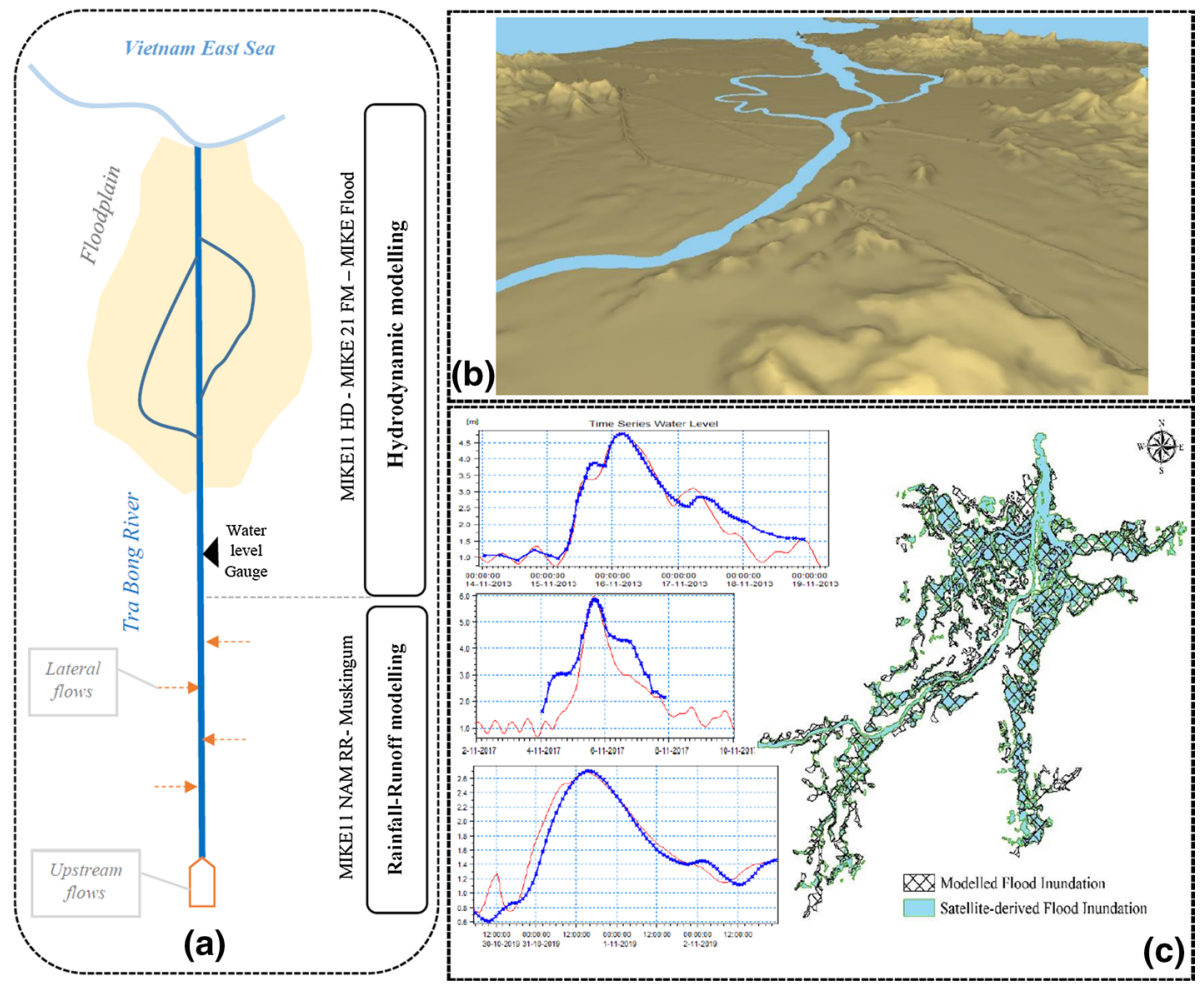

Fig. 8 Hydraulic schematization and 1D, 2D model performances

3D view of the floodplain where several structures such as dikes, roads (highways, railways), and sluices are integrated into the model due to their significant impacts on flooding behaviors. In this study, the 1D and 2D models were then linked together using a coupling technique to simulate flood flows and overbank flows. The lateral link was chosen for simulating overbank flows from the river into floodplains using a structure equation or a relation of discharge and water level, in which every calculation point in the river and its tributaries was linked to every cell in the 2D model or mesh element in the floodplains.

To evaluate the performances of this modeling system, the simulated water level was compared with the observed water level at the Chau O gauging station (Fig. 1), and the simulated flood inundation was also compared with the satellite-derived flood inundation. The model performances are graphically plotted in Fig. 8c. For the 1D model, the results are presented here for events that occurred in 2013, 2017, and 2019. For the 2D model, only the flood inundation captured in the 2019 flood event is illustrated here. It can be observed that there is a high degree of conformity in the phase and the amplitude of the water level hydrograph at Chau O station. Particularly, the peak water levels and the time of the peak values are generally well simulated for all cases. Table 3 lists the goodnessof-fit errors between simulated and observed data. For the flood events of 2013 and 2019, the modeling system performed fairly well in terms of NSE, RMSE, and RPE. The flood shapes of the 2013 and 2019 events are slightly different due to some uncertainties during the running of the modeling system. A possible main reason could be the usage of the 
Table 3 Model evaluation statistics for the calibration and validation processes

\begin{tabular}{lllllllll}
\hline Flood events & \multicolumn{3}{l}{ 1D hydraulic model } & & \multicolumn{3}{l}{ 2D hydraulic model } \\
\cline { 2 - 3 } \cline { 7 - 8 } & NSE & $\begin{array}{l}\text { RMSE- } \\
\text { Water level } \\
(\mathrm{m})\end{array}$ & RPE $\%$ & & F1 & F2 & $\begin{array}{l}\text { RMSE- } \\
\text { Water depth } \\
(\mathrm{m})\end{array}$ \\
\hline 2019 & 0.72 & 0.19 & & 0.7 & & 0.55 & 0.37 & 0.96 \\
2017 & 0.30 & 0.94 & -2.13 & & - & - & - \\
2013 & 0.80 & 0.36 & 0.48 & & - & - & - \\
\hline
\end{tabular}

results of the hydrological model as input data in the hydrodynamic models. Obviously, the hydrographs obtained from the rainfall-runoff model do not represent exactly the hydrological conditions of the basin. In 2017 the model performance was much lower in terms of NSE and RMSE due to the differences of two flood volumes. One of the reasons can be interpreted as the effect of the coarse existing rain gauge network and low intensity of satellite rainfall, from which the rainfall distribution might not be observed well during the period, leading to a decrease of total flood volume.

It can be observed that the reproduced inundation exhibits good agreement with the satellite-derived inundation. The modeled flood inundation extent is evaluated as relatively consistent with the satellite-derived one $(\mathrm{F} 1>0.5)$; however, it was slightly overpredicted by the model $(\mathrm{F} 2<0.5)$. As for flood depths, the depths estimated from satellite images and DEMs are strongly controlled by the ground topography, or in other words, the estimation of inundation depths is mainly directly dependent on the quality of ground elevation datasets (Nguyen et al. 2016; Cohen et al. 2018). In this study, we downloaded a free DEM with a lower quality therefore, we only used the estimated flood depth values as a reference factor for evaluating the model performance. Examining 30 random locations evenly allocated over the flooded areas by comparing flood depths estimated from the satellite data and the model, RMSE is $0.96 \mathrm{~m}$ (Table. 3), in which maximum depth error is $2.5 \mathrm{~m}$, and minimum depth error is $0.1 \mathrm{~m}$. According to the statistical metrics, it can be concluded that the hydrological and hydraulic models used for this case study again performed rather well for the flood flows simulation in the river and the floodplain.

Although the modeling system with many types of models was applied in the ungauged river basin, it still exhibited an advantage for mapping the inundation extent. One of the major challenges of this study includes the lack of observed information such as rainfall and river discharges, as well as the non-availability of the observed flood depths in the floodplains. In the recent past, flood models in combination with satellite imageries and GIS were commonly used for flood risk assessment. However, the combination of flood model and remote sensing-based products, including precipitation and images for ungauged basins, was rarely taken into account, especially in Southeast Asia. In this presented approach, the optimal parameter search algorithm is very important in transferring the parameters from the borrowed basin to the study basin. In the process of transferring the lumped conceptual model to the semi-distributed model, the more sub-basins a model has, the more computational time is needed to determine optimal parameter sets. Sub-daily variability of rainfall is extremely significant for the accuracy of flood modeling. Shrestha et al. (2019b) also demonstrated that sub-daily information from satellite precipitation used for temporal downscaling of rain gauge data provides the best option for accurate hydrological modeling of floods. Therefore, it is recommended to examine and evaluate the accuracy of potential satellite rainfall products over selected areas in order to select a suitable 
one before applying the proposed approach. We believe that estimating inundation depths from an inundation map derived from satellite imageries with an associated digital elevation model will support the model calibration and verification processes in data-scarce and ungauged river basins. However, major limitations include obtaining accurate high-resolution DEMs and dealing with fragmented flood inundation domains (Cohen et al. 2019).

\subsection{Probability analysis and flood hazards}

\subsubsection{Rainfall probability analysis}

The maximum daily rainfall at the Tra Bong gauging station was chosen instead of using flood discharge peaks for probability analysis. To analyze the rainfall frequency characteristics, the GEV distribution (Coles 2001), which popularly uses the method of block maxima, was applied to fit the annual maximum rainfall and then to estimate the 10-, 20-, 50-, and 100-year return periods. The method of Maximum Likelihood Estimation, which has the ability for accounting for the non-stationary model fitting the analysis of the extreme values, was used to obtain the GEV parameters. Figure 9 shows the maxima values (bar plot) and the results of the GEV distribution fitted (solid curve) and the $95 \%$ confidence interval (dashed curves). Based on these curves, the return levels and their corresponding estimations can be determined easily.

For flood hazard mapping, different sub-daily rainfall patterns were selected based on the sub-daily rainfall observed by the remote sensing technique. To select a sub-daily rainfall pattern for each return period, the maximum 1-day rainfall volumes of the return period and the satellite data were compared to identify the most equivalent ones. After that, a ratio factor was computed based on the two rainfall volumes and then multiplied with the selected rainfall pattern for creating the design rainfall hyetograph.

\subsubsection{Flood hazard mapping}

Flood hazard is normally considered according to local conditions of a certain area or region. In different regions with various natural characteristics such as topographies, flood behaviors, and/or people gathering, flood intensity is classified differently (Mani et al. 2014; Luu et al. 2018). The flood hazard map guidelines typically established for Germany
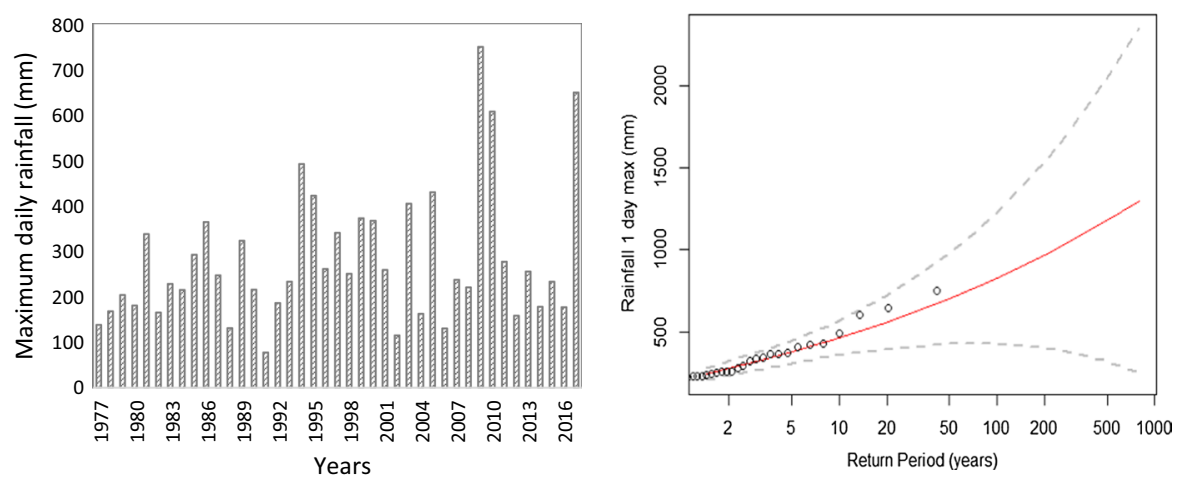

Fig. 9 Maxima rainfall values and rainfall probability and 95\% CI 
Table 4 Flood inundation intensity classification corresponding to hazard categories

\begin{tabular}{llll}
\hline Categories & Water depth & Water velocity & Water duration \\
\hline High & $>2.0 \mathrm{~m}$ & $>2.0 \mathrm{~m} / \mathrm{s}$ & $>24 \mathrm{~h}$ \\
Medium & $0.5-2.0 \mathrm{~m}$ & $0.5-2.0 \mathrm{~m} / \mathrm{s}$ & $6-24 \mathrm{~h}$ \\
Low & $<0.5 \mathrm{~m}$ & $<0.5 \mathrm{~m} / \mathrm{s}$ & $<6 \mathrm{~h}$ \\
\hline
\end{tabular}

by the German working group of the Federal States on Water Issues were applied as a reference for mapping flood hazards in the study area. According to LAWA (2006), flood hazard maps provide information in terms of the relationship between the flood probability and the flood inundation intensity, whereby water depth is the most important damage parameter because it potentially impacts animals, humans, and infrastructure. However, high flow velocity combined with high water depth will increase risks as well. The duration of flooding is a third important parameter due to its potential impacts on dike failure or crops. Flood intensity classifications are referred by three main categories including Low, Medium, and High. Table 4 gives an example of the three categories corresponding to three main flood components (depth, velocity, and duration), in which, particularly, flood inundation duration is not mentioned in the guideline. However, we classified that flood component into the same categories based on the flood periods and expert opinions.

Figure 10 shows the flood hazard maps for a 10-, 20-, 50-, and 100-year return period. It can be seen that the flood inundation areas and hazard levels become larger when the flood return periods increase. The maps also illustrate that the flooded areas on the left bank are clearly larger than on the right bank for all return periods. For further studies, these maps can be used as useful references for flood hazard assessments or flood risk assessments.

\section{Conclusions}

The flood modeling system (MIKE11 NAM, MIKE11 HD, MIKE21 FM, and MIKE Flood) in combination with the satellite-based precipitation product (CMORPH_CRT) and the synthetic aperture radar imagery (Sentinel-1A) was successfully set up and employed to simulate the complex process from rainfall-runoff to flow dynamic in the river and floodplains of the Tra Bong river basin located in central Vietnam. The integrated approach with many distinct methods applied in this study enables us to have a better understanding of flooding and inundation regimes in data-scarce and ungauged coastal river basins.

Satellite precipitation datasets will be crucial to numerical modeling applications in the future. In our study, we also focused on comparing the satellite precipitation products with ground-measured data. According to the obtained results, it is highly recommended that satellite precipitation may be examined and validated with ground-measured stations to detect and adjust errors as well as to choose an appropriate product for model applications. Moreover, it is important to know that rainfall data are the main factor that strongly affects model outputs in this approach. In this study, CMORPH_CRT was employed because it showed better performances compared to the other product when we examined at 1-day and 1-h temporal resolutions at each station. Therefore, applying the rainfall temporal downscaling technique and using the adjusted satellite rainfall indicated that the flood model can adequately simulate the flood peaks in terms of values and time of occurrence. This rainfall data, together with the new generation of SAR imageries, which was just opened for free 

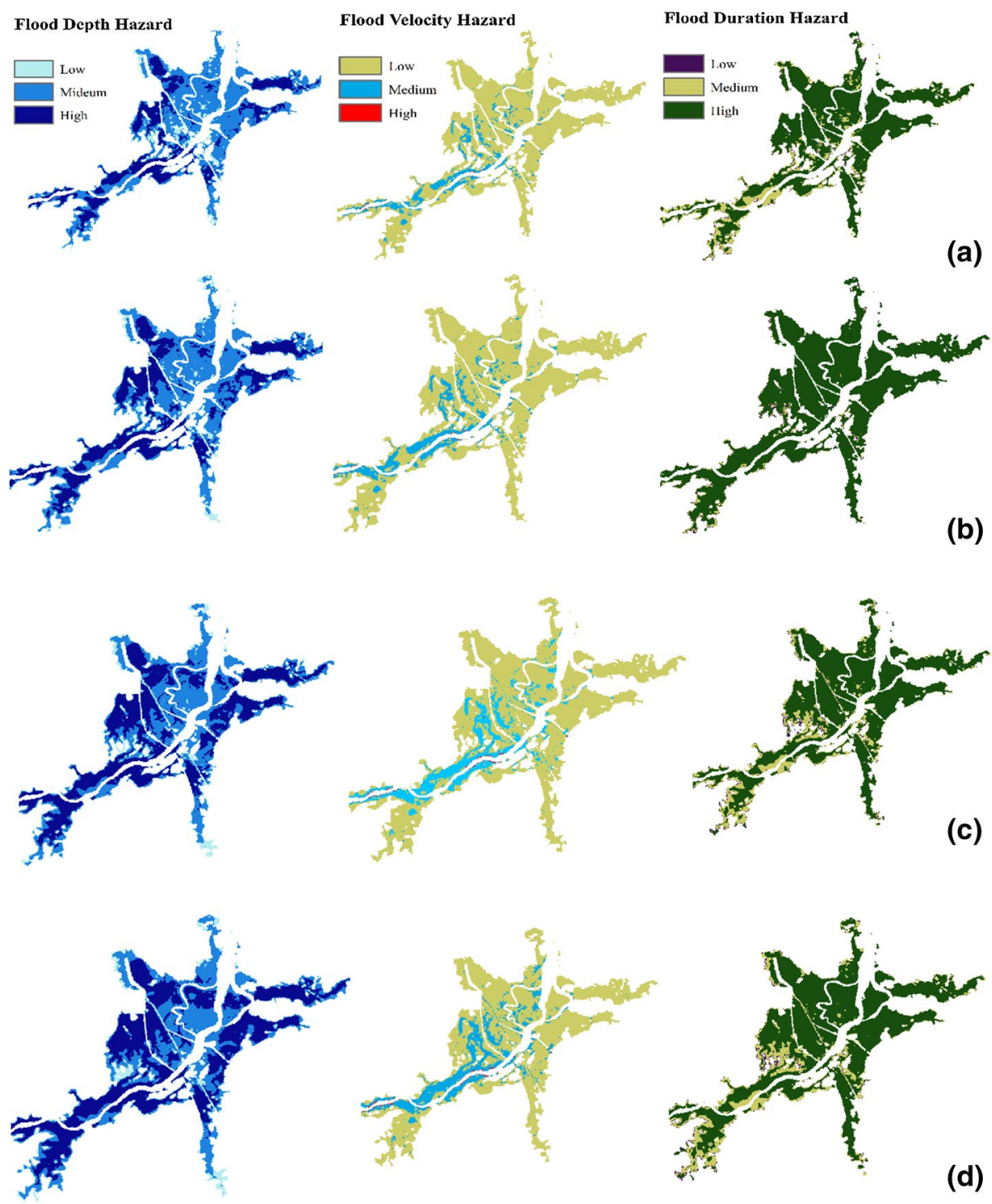

Fig. 10 Flood hazard maps of flood depth, flood velocity, and flood duration corresponding to return periods of $10(\mathbf{a}), 20(\mathbf{b}), 50(\mathbf{c})$, and $100(\mathbf{d})$ years

access in Southeast Asia, will be very helpful for studying flood inundation, particularly in ungauged river basins.

The study introduced the four main steps of transforming a lumped model to a semi-distributed model. The results illustrated that the drawbacks of this kind of model are partly handled and the number of potential model parameter sets is increased for the application of the regionalization techniques. However, it is noted that this approach is mostly suitable for small- and medium-sized river basins where measured data are not available or limited. In addition, the simulation results of the other models also demonstrated that the 
entire flood modeling system performed fairly well the flood hydrographs and inundation in the Tra Bong basin. The flood hazard maps were then created for the Tra Bong river basin based on the flood probability (10-, 20-, 50- and 100-year return period) and the flood intensity (depths, velocity, and duration). We found that the inundated areas and hazard levels have a linear relationship with the flood return periods, and the floodplain on the left bank is heavily affected by flooding and inundation. We can conclude that the methods and the proposed approach applied in this study did bring up a feasible solution for mapping flood hazards in data-scarce and ungauged river basins.

Uncertainties in this work are visible and cannot be avoided. Sources of uncertainties may come from the models themselves (model parameters and structures), input data (e.g., data errors or accuracy of satellite precipitation datasets), quality and revisit time of satellite imageries. Although the model performances in this work need to be improved and conducted with further validation to evaluate the efficiency of the approach, it illustrated that advanced hydrological and hydraulic models in combination with satellite products play an essential role in assessing flood hazards or flood risks for not only gauged river basins but also for data-scarce or ungauged river basins to obtain an overview picture of flooding and inundation.

Acknowledgements The first author would like to acknowledge the German Academic Exchange Service for their financial support. The authors are particularly grateful to DHI Wasy GmbH Company for the MIKE model licenses. The authors are also extremely thankful to the institutions such as the European Space Agency, Japan Aerospace Exploration Agency, National Oceanic and Atmospheric Administration-Climate Prediction Center of the US, and National Hydro-Meteorological Service of Vietnam for providing useful satellite data and measured data for this study. Special thanks go to the editor and the three anonymous reviewers for their constructive comments.

Authors' contributions TXM proposed and drafted the manuscript. MF supported TXM in the modeling part and revised as well as supervised the methodology. All authors revised and approved the final manuscript.

Funding Open Access funding enabled and organized by Projekt DEAL. This research has been supported by the German Academic Exchange Service (DAAD).

Availability of data and materials Not applicable.

Code availability Not applicable.

\section{Compliance with ethical standards}

Conflicts of interest Not applicable.

Open Access This article is licensed under a Creative Commons Attribution 4.0 International License, which permits use, sharing, adaptation, distribution and reproduction in any medium or format, as long as you give appropriate credit to the original author(s) and the source, provide a link to the Creative Commons licence, and indicate if changes were made. The images or other third party material in this article are included in the article's Creative Commons licence, unless indicated otherwise in a credit line to the material. If material is not included in the article's Creative Commons licence and your intended use is not permitted by statutory regulation or exceeds the permitted use, you will need to obtain permission directly from the copyright holder. To view a copy of this licence, visit http://creativecommons.org/licenses/by/4.0/. 


\section{References}

Abdikan S, Sanli FB, Ustuner M, Calò F (2016) Land cover mapping using sentinel-1 SAR data. Int Arch Photogramm Remote Sens Spat Inf Sci ISPRS Arch 41:757-761. https://doi.org/10.5194/isprsarchi ves-XLI-B7-757-2016

Adjei KA, Ren L, Appiad-Adfei EK, Odai SN (2015) Application of satellite-derived rainfall for hydrological modelling in the data-scarce Black Volta trans-boundary basin. Hydrol Res 46:777-791. https:// doi.org/10.2166/nh.2014.111

Arsenault R, Brissette FP (2014) Continuous streamflow prediction in ungauged basins: the effects of equifinality and parameter set selection on uncertainty in regionalization approaches. Water Resour Res 50:6135-6153. https://doi.org/10.1002/2013WR014898

AusAID (2003) Flood hazard reduction in Quang Ngai, Vietnam (in vietnamese)

Baldassarre GD, Schumann G, Bates PD (2009) A technique for the calibration of hydraulic models using uncertain satellite observations of flood extent. J Hydrol 367:276-282. https://doi.org/10.1016/j.jhydr ol.2009.01.020

Bardossy A (2007) Calibration of hydrological model parameters for ungauged catchments. Hydrol Earth Syst Sci 11:703-710. https://doi.org/10.5194/hess-11-703-2007

Barthélémy S, Ricci S, Morel T et al (2018) On operational flood forecasting system involving 1D/2D coupled hydraulic model and data assimilation. J Hydrol 562:623-634. https://doi.org/10.1016/j.jhydrol. 2018.05.007

Bates PD (2004) Remote sensing and flood inundation modelling. Hydrol Process 18:2593-2597. https:// doi.org/10.1002/hyp.5649

Binh LTH, Umamahesh NV, Rathnam EV (2019) High-resolution flood hazard mapping based on nonstationary frequency analysis: case study of Ho Chi Minh City, Vietnam. Hydrol Sci J 64:318-335. https://doi.org/10.1080/02626667.2019.1581363

Bon T, Quynh N, Ngoc V (2016) Predicting inundation caused by storms and super storms in the coastal regions of Vietnam. Vietnam J Sci Technol 33:1-8

Boughton W, Chiew F (2007) Estimating runoff in ungauged catchments from rainfall, PET and the AWBM model. Environ Model Softw 22:476-487. https://doi.org/10.1016/j.envsoft.2006.01.009

Chang CH, Lee H, Hossain F et al (2019) A model-aided satellite-altimetry-based flood forecasting system for the Mekong River. Environ Model Softw 112:112-127. https://doi.org/10.1016/j.envsoft.2018.11. 017

Chen H, Ito Y, Sawamukai M, Tokunaga T (2015) Flood hazard assessment in the kujukuri plain of Chiba prefecture, Japan, based on GIS and multicriteria decision analysis. Nat Hazards 78:105-120. https:// doi.org/10.1007/s11069-015-1699-5

Cheng Y, Andersen OB (2011) Multimission empirical ocean tide modeling for shallow waters and polar seas. J Geophys Res Ocean 116:1-11. https://doi.org/10.1029/2011JC007172

Chow VT (1959) Open-channel hydraulics. McGraw-Hill Book Co., New York

Cohen S, Brakenridge GR, Kettner A et al (2018) Estimating floodwater depths from flood inundation maps and topography. J Am Water Resour Assoc 54:847-858. https://doi.org/10.1111/1752-1688.12609

Cohen S, Raney A, Munasinghe D et al (2019) The Floodwater Depth Estimation Tool (FwDET v2.0) for improved remote sensing analysis of coastal flooding. Nat Hazards Earth Syst Sci 19:2053-2065. https://doi.org/10.5194/nhess-19-2053-2019

Coles S (2001) An introduction to statistical modeling of extreme values. Springer, London

Cuong HD, Thuy NB, Van HN, Tien DD (2017) Assessment of the risk of typhoons and storm surge in coastal areas of Vietnam. J Hydro-Meteorol 12:1-9

Dang NM, Babel MS, Luong HT (2011) Evaluation of food risk parameters in the Day River Flood Diversion Area, Red River Delta. Vietnam Nat Hazards 56:169-194. https://doi.org/10.1007/ s11069-010-9558-X

De Moel H, Van Alphen J, Aerts JCJH (2009) Flood maps in Europe-methods, availability and use. Nat Hazards Earth Syst Sci 9:289-301. https://doi.org/10.5194/nhess-9-289-2009

Dewan AM, Islam MM, Kumamoto T, Nishigaki M (2007) Evaluating flood hazard for land-use planning in greater Dhaka of Bangladesh using remote sensing and GIS techniques. Water Resour Manag 21:1601-1612. https://doi.org/10.1007/s11269-006-9116-1

DHI (2019a) MIKE flood-modelling of river flooding. Denmark

DHI (2019b) MIKE 21 flow model \& MIKE 21 flood screening tool-hydrodynamic module. Denmark

DHI (2017a) MIKE11 - a modelling system for Rivers and Channels. Denmark

DHI (2017b) MIKE 21 Toolbox. Global tide model: tidal prediction. Denmark 
Di BG, Schumann G, Bates PD (2009) A technique for the calibration of hydraulic models using uncertain satellite observations of flood extent. J Hydrol 367:276-282. https://doi.org/10.1016/j.jhydrol.2009.01. 020

Douglas I (2017) Flooding in African cities, scales of causes, teleconnections, risks, vulnerability and impacts. Int J Disaster Risk Reduct 26:34-42. https://doi.org/10.1016/j.ijdrr.2017.09.024

Duan QY, Gupta VK, Sorooshian S (1993) Shuffled complex evolution approach for effective and efficient global minimization. J Optim Theory Appl 76:501-521. https://doi.org/10.1007/BF00939380

Engdahl ME, Hyyppä JM (2003) Land-cover classification using multitemporal ERS-1/2 InSAR data. IEEE Trans Geosci Remote Sens 41:1620-1628. https://doi.org/10.1109/TGRS.2003.813271

Feyen L, Dankers R, Bódis K et al (2009) Flood hazard in Europe in an ensemble of regional climate scenarios. J Geophys Res Atmos 114:47-62. https://doi.org/10.1029/2008JD011523

Ficchì A, Perrin C, Andréassian V (2016) Impact of temporal resolution of inputs on hydrological model performance: an analysis based on 2400 flood events. J Hydrol 538:454-470. https://doi.org/10.1016/j. jhydrol.2016.04.016

George J, Arcement J, Schneider VR (1989) Guide for selecting manning's roughness coefficients for natural channels and flood plains

Haile AT, Yan F, Habib E (2015) Accuracy of the CMORPH satellite-rainfall product over Lake Tana Basin in Eastern Africa. Atmos Res 163:177-187. https://doi.org/10.1016/j.atmosres.2014.11.011

He Y, Bárdossy A, Zehe E (2011) A review of regionalisation for continuous streamflow simulation. Hydrol Earth Syst Sci 15:3539-3553. https://doi.org/10.5194/hess-15-3539-2011

Horritt MS, Bates PD (2002) Evaluation of 1D and 2D numerical models for predicting river flood inundation. J Hydrol 268:87-99. https://doi.org/10.1016/S0022-1694(02)00121-X

Horritt MS, Di Baldassarre G, Bates PD, Brath A (2007) Comparing the performance of a 2-D finite element and a 2-D finite volume model of floodplain inundation using airborne SAR imagery. Hydrol Process 21:2745-2759. https://doi.org/10.1002/hyp.6486

Huong NTT (2010) Flood protection and drainage in Tra Khuc-Ve River Basin, Quang Ngai Province. Project final report, Vietnam Academy for Water Resources (in Vietnamese)

Khalil RZ, Saad-ul-Haque A (2018) InSAR Coherence-based land cover classification of Okara, Pakistan. Egypt J Remote Sens Space Sci 21:S23-S28. https://doi.org/10.1016/j.ejrs.2017.08.005

Kreft S, Eckstein D, Junghans L et al (2015) Global climate risk index 2015. Berlin

LAWA (2006) Flood hazard map guidelines of the German Working Group of the Federal States on Water Issues

Lebecherel L, Andréassian V, Perrin C (2016) On evaluating the robustness of spatial-proximity-based regionalization methods. J Hydrol 539:196-203. https://doi.org/10.1016/j.jhydrol.2016.05.031

Luu C, Von Meding J, Kanjanabootra S (2018) Assessing flood hazard using flood marks and analytic hierarchy process approach: a case study for the 2013 flood event in Quang Nam, Vietnam. Nat Hazards 90:1031-1050. https://doi.org/10.1007/s11069-017-3083-0

Maggioni V, Meyers PC, Robinson MD (2016) A review of merged high-resolution satellite precipitation product accuracy during the Tropical Rainfall Measuring Mission (TRMM) era. J Hydrometeorol 17:1101-1117. https://doi.org/10.1175/JHM-D-15-0190.1

Makinde E, Oyelade O (2018) Land cover mapping using sentinel-1 SAR satellite imagery of lagos state for 2017. Proceedings 2:1399. https://doi.org/10.3390/proceedings2221399

Makungo R, Odiyo JO, Ndiritu JG, Mwaka B (2010) Rainfall-runoff modelling approach for ungauged catchments: a case study of Nzhelele River sub-quaternary catchment. Phys Chem Earth 35:596607. https://doi.org/10.1016/j.pce.2010.08.001

Mani P, Chatterjee C, Kumar R (2014) Flood hazard assessment with multiparameter approach derived from coupled 1D and 2D hydrodynamic flow model. Nat Hazards 70:1553-1574. https://doi.org/10. 1007/s11069-013-0891-8

McCuen RH (1998) Hydrologic analysis and design. Prentice-Hall, Hoboken

Mcvittie A (2019) SENTINEL-1 flood mapping tutorial. http://step.esa.int/docs/tutorials/tutorial_s1flo odmapping.pdf. Accessed 5 Mar 2020

Merz R, Blöschl G (2004) Regionalisation of catchment model parameters. J Hydrol 287:95-123. https:// doi.org/10.1016/j.jhydrol.2003.09.028

Mosquera-Machado S, Ahmad S (2007) Flood hazard assessment of Atrato River in Colombia. Water Resour Manag 21:591-609. https://doi.org/10.1007/s11269-006-9032-4

Nam DH, Udo K, Mano A (2015) Future fluvial flood risks in Central Vietnam assessed using global super-high-resolution climate model output. J Flood Risk Manag 8:276-288. https://doi.org/10. 1111/jfr3.12096 
Nga PH, Takara K, Van Cam N (2018) Integrated approach to analyze the total flood risk for agriculture: the significance of intangible damages - a case study in Central Vietnam. Int J Disaster Risk Reduct 31:862-872. https://doi.org/10.1016/j.ijdrr.2018.08.001

Nguyen NY, Ichikawa Y, Ishidaira H (2016) Estimation of inundation depth using flood extent information and hydrodynamic simulations. Hydrol Res Lett 10:39-44. https://doi.org/10.3178/hrl.10.39

Nhung DT (2016) Flood planning in central Vietnam. Vietnam J Sci Technol Water Resour 160-173

Ntajal J, Lamptey BL, Mahamadou IB, Nyarko BK (2017) Flood disaster risk mapping in the Lower Mono River Basin in Togo, West Africa. Int J Disaster Risk Reduct 23:93-103. https://doi.org/10. 1016/j.ijdrr.2017.03.015

Ostad-Ali-Askari K, Shayannejad M, Ghorbanizadeh-Kharazi H (2016) Artificial neural network for modeling nitrate pollution of groundwater in marginal area of Zayandeh-rood River, Isfahan. Iran KSCE J Civ Eng 21:134-140. https://doi.org/10.1007/s12205-016-0572-8

Ostad-Ali-Askari K, Ghorbanizadeh Kharazi H, Shayannejad M, Zareian MJ (2019) Effect of management strategies on reducing negative impacts of climate change on water resources of the IsfahanBorkhar aquifer using MODFLOW. River Res Appl 35:611-631. https://doi.org/10.1002/rra.3463

Ostad-Ali-Askari K, Shayannejad M, Ghorbanizadeh KH, Zareian MJ (2020) Effect of climate change on precipitation patterns in an arid region using GCM models: case study of Isfahan-Borkhar Plain. Nat Hazards Rev. https://doi.org/10.1061/(ASCE)NH.1527-6996.0000367

Ozawa G, Inomata H, Shiraishi Y, Fukami K (2011) Applicability of gsmap correction method to typhoon "morakot" in Taiwan. J Japan Soc Civ Eng Ser B1 Hydraulic Eng 67:I_445-I_450. https://doi.org/10. 2208/jscejhe.67.i_445

Pagliero L, Bouraoui F, Diels J et al (2019) Investigating regionalization techniques for large-scale hydrological modelling. J Hydrol 570:220-235. https://doi.org/10.1016/j.jhydrol.2018.12.071

Prinos P (2008) Review of flood hazard mapping. http://www.floodsite.net/html/partner_area/project_docs/ T03_07_01_Review_Hazard_Mapping_V4_3_P01.pdf. Accessed 18 June 2019

Rai PK, Dhanya CT, Chahar BR (2018) Coupling of 1D models (SWAT and SWMM) with 2D model (iRIC) for mapping inundation in Brahmani and Baitarani river delta. Nat Hazards 92:1821-1840. https://doi. org/10.1007/s11069-018-3281-4

Ryo M, Valeriano OCS, Kanae S, Dang N (2014) Temporal downscaling of daily gauged precipitation by application of a satellite product for flood simulation in a poorly gauged basin and its evaluation with multiple regression analysis. J Hydrometeorol 15:563-580. https://doi.org/10.1175/JHM-D-13-052.1

Sadeh Y, Cohen H, Maman S, Blumberg DG (2018) Evaluation of manning's n roughness coefficient in arid environments by using SAR backscatter. Remote Sens 10:1-14. https://doi.org/10.3390/rs10101505

Schumann G, Matgen P, Hoffmann L et al (2007) Deriving distributed roughness values from satellite radar data for flood inundation modelling. J Hydrol 344:96-111. https://doi.org/10.1016/j.jhydrol.2007.06. 024

Shrestha BB, Perera EDP, Kudo S et al (2019a) Assessing flood disaster impacts in agriculture under climate change in the river basins of Southeast Asia. Springer, Netherlands

Shrestha PK, Shrestha S, Ninsawat S (2019b) How significant is sub-daily variability of rainfall for hydrological modelling of floods? A satellite based approach to sub-daily downscaling of gauged rainfall. Meteorol Appl 26:288-299. https://doi.org/10.1002/met.1762

Smith LC (1997) Satellite remote sensing of river inundation area, stage, and discharge: a review. Hydrol Process 11:1427-1439. https://doi.org/10.1002/(sici)1099-1085(199708)11:10\%3c1427::aid-hyp473\% 3e3.3.co; $2-\mathrm{j}$

Song X, Zhang J, Zhan C et al (2015) Global sensitivity analysis in hydrological modeling: review of concepts, methods, theoretical framework, and applications. J Hydrol 523:739-757. https://doi.org/10. 1016/j.jhydrol.2015.02.013

Stammer D, Ray R, Andersen OB et al (2014) Accuracy assessment of global barotropic ocean tide models. Rev Geophys 52:243-282. https://doi.org/10.1002/2014RG000450.Received

Swain JB, Patra KC (2017) Streamflow estimation in ungauged catchments using regionalization techniques. J Hydrol 554:420-433. https://doi.org/10.1016/j.jhydrol.2017.08.054

Tang Y, Reed P, Wagener T, Van Werkhoven K (2007) Comparing sensitivity analysis methods to advance lumped watershed model identification and evaluation. Hydrol Earth Syst Sci 11:793-817. https://doi. org/10.5194/hess-11-793-2007

Tegegne G, Kim YO (2018) Modelling ungauged catchments using the catchment runoff response similarity. J Hydrol 564:452-466. https://doi.org/10.1016/j.jhydrol.2018.07.042

Teng J, Jakeman AJ, Vaze J et al (2017) Flood inundation modelling: a review of methods, recent advances and uncertainty analysis. Environ Model Softw 90:201-216. https://doi.org/10.1016/j.envsoft.2017.01. 006 
Thanh N, Matsumoto J, Kamimera H, Bui HH (2013) Monthly adjustment of Global Satellite Mapping of Precipitation (GSMaP) data over the VuGia ThuBon River Basin in Central Vietnam using an artificial neural network. Hydrol Res Lett 7:85-90. https://doi.org/10.3178/hrl.7.85

Tran P, Marincioni F, Shaw R et al (2008) Flood risk management in Central Viet Nam: challenges and potentials. Nat Hazards 46:119-138. https://doi.org/10.1007/s11069-007-9186-2

Waghwala RK, Agnihotri PG (2019) Flood risk assessment and resilience strategies for flood risk management: a case study of Surat City. Int J Disaster Risk Reduct 40:101155. https://doi.org/10.1016/j.ijdrr. 2019.101155

Wallner M, Haberlandt U, Dietrich J (2013) A one-step similarity approach for the regionalization of hydrological model parameters based on self-organizing maps. J Hydrol 494:59-71. https://doi.org/10. 1016/j.jhydrol.2013.04.022

Werner MGF, Hunter NM, Bates PD (2005) Identifiability of distributed floodplain roughness values in flood extent estimation. J Hydrol 314:139-157. https://doi.org/10.1016/j.jhydrol.2005.03.012

Publisher's Note Springer Nature remains neutral with regard to jurisdictional claims in published maps and institutional affiliations.

\section{Authors and Affiliations}

\section{Manh Xuan Trinh $^{1}$ (D) Frank Molkenthin $^{1}$}

\section{Manh Xuan Trinh}

Trinh.XuanManh@b-tu.de

1 Brandenburg University of Technology Cottbus-Sentenberg (BTU) Chair Hydrology, Platz der Deutschen Einheit 1, 03046 Cottbus, Germany 